\title{
Local Costs of Distribution, International Trade Costs and Micro Evidence on the Law of One Price
}

(Forthcoming in Journal of International Economics)

\author{
Rahul Giri ${ }^{*}$ \\ Instituto Tecnologico Autonomo de Mexico $\ddagger$
}

18 August, 2011

\begin{abstract}
This paper connects trade flows to deviations from the law of one price (LOOP) in a structural model of trade and retailing. It accounts for the observed cross-country dispersion in prices of goods, based on retail price survey data, by focusing on two sources of goods market segmentation - (i) international trade costs, and (ii) non-traded input costs of distribution. I find that a multi-sector Ricardian trade model, ala Eaton-Kortum, augmented with a distribution sector, can account for the average price dispersion for a basket of goods fully and generates 70 percent of the variation in price dispersion across goods within the basket. While tradability of goods is important in explaining the average price dispersion for the basket of goods, distribution costs are important in explaining why, within the basket, some goods show more price dispersion than others.
\end{abstract}

JEL Codes: F11, F15

Keywords: Trade, international trade costs, distribution costs, law of one price, price dispersion

*I am grateful to Caroline Betts, Vincenzo Quadrini, Guillaume Vandenbroucke, Doug Joines and Yong Kim for their advice and suggestions. I have benefited from conversations with Kei-Mu Yi, Mario Crucini, Chris Telmer, Ariel Burstein, Timothy Kehoe, Igor Livshits and Saralees Nadarajah. Comments from the participants at the seminars at Banco De Mexico and CIDE, SED Annual Meetings, Midwest Macro Meetings, the Dynamics Seminar at USC and the XII Workshop on Dynamic Macroeconomics have been very helpful. I am also thankful to Michael E. Waugh for sharing data. All remaining errors are mine.

${ }^{\dagger}$ Corresponding author

${ }^{\ddagger}$ Contact Address: Centro de Investigacion Economica (CIE), Instituto Tecnologico Autonomo de Mexico (ITAM), Av. Camino Santa Teresa \# 930, Col. Heroes de Padierna, Del. Magdalena Contreras, C.P. 10700 Mexico, D.F.. E-mail: rahul.giri@itam.mx, Tel: +52(55)56284197, Fax: +52(55)56284058 


\section{Introduction}

In frictionless markets, arms' length trade in goods will arbitrage away price differentials across countries, such that the absolute law of one price (LOOP) holds. As a result, two approaches have been used to measure market segmentation: One approach infers the degree of segmentation from the volume of bilateral trade flows, ${ }^{1}$ the other deduces segmentation from the deviations from LOOP. ${ }^{2}$ The two approaches developed largely independently, and both conclude that international goods markets are highly segmented.

This paper connects trade flows to deviations from LOOP in a structural model of trade and retailing. My objective is to account for the observed cross-country dispersion in prices of goods by focusing on two commonly cited sources of goods market segmentation - (i) international trade costs or barriers to trade and (ii) non-traded input costs of distributing and retailing goods within local markets.

Most empirical work focusing on measuring deviations from LOOP is limited by the use of price index data, or of prices of a very narrow set of individual goods. Much of the empirical evidence, therefore, concerns the volatility and persistence of changes in relative prices, although the first-order restrictions from theory are on absolute LOOP deviations. Crucini, Telmer and Zachariadis (2005), however, compile local-currency retail prices on a large cross-section of goods across 13 European Union (EU) countries to study cross-country price dispersion. ${ }^{3}$

Using this same data set, I account for two moments of the distribution of cross-country dispersion in prices of goods: (i) average price dispersion across goods, which is about 28 percent, and (ii) the variation in price dispersion across goods, which ranges from a minimum of 2 percent to a maximum of 83 percent. The first moment provides a measure of market segmentation for a basket of a large variety of goods. The second moment tells us if, within the basket, markets are more segmented for some goods than others.

\footnotetext{
${ }^{1}$ Krugman (1991), McCallum (1995), Eaton and Kortum (2002), and Waugh (2009).

${ }^{2}$ Knetter (1993), Campa and Wolf (1997), Burstein, Neves and Rebelo (2003).

${ }^{3}$ Rogers (2001), Engel and Rogers (2004), Crucini and Shintani (2008), and Engel, Rogers and Wang (2005) also use broad cross-sectional dataset of retail prices, but these data are smaller in coverage of goods. Also, none of these studies look at absolute deviations from LOOP.
} 
I develop a model of trade and retailing by incorporating local costs of distribution in the multi-country Ricardian model of trade due to Eaton and Kortum (2002) (henceforth EK). ${ }^{4}$ Countries trade a continuum of goods, differentiated in costs (or productivity levels) subject to bilateral and asymmetric trade costs, that are estimated using data on bilateral trade flows. The retail good delivered to the consumer is a combination of the individual traded good and non-traded distribution services. The units of distribution services that are needed to deliver one unit of a retail good vary across goods and countries, and are calibrated to match data on distribution margins across countries.

Dispersion in retail prices of goods is driven by differences in the degree of tradability of goods and the differences in the use of distribution services, where tradability of goods depends on trade costs and the elasticity of substitution. For the benchmark value of the elasticity of substitution (or elasticity of trade), ${ }^{5}$ which falls in the middle of the range of values estimated by EK, I find that the model can account for 96 percent of the average price dispersion and 32 percent of the variation in price dispersion across goods. To illustrate how tradability alone drives LOOP deviations, I present a version of the model that abstracts from distribution costs. Without distribution costs, the model generates 84 percent of average price dispersion but only 19 percent of the variation in price dispersion. Thus, incorporating differences in costs of distribution across countries in the EK model helps to match the average price dispersion for a basket of goods almost perfectly and improves the model's performance in generating the variation.

The inability of the model to match the variation in price dispersion results from insufficient heterogeneity in tradability and distributions costs across goods. To capture greater heterogeneity in the two sources of LOOP deviations, I extend the baseline model to a multi-sector framework. Now, countries trade goods across multiple sectors. This allows us to exploit the differences in trade volumes and distribution costs across sectors and countries, observed in the data. The sectoral model with distribution costs can account for

\footnotetext{
${ }^{4}$ The authors generalized the two country model of Dornbusch, Fischer and Samuelson (1977) to a multicountry model. Alvarez and Lucas (2007) showed the existence and uniqueness of equilibrium in the multicountry model.

${ }^{5}$ In the EK model the elasticity of substitution is governed by the parameter which governs the heterogeneity in idiosyncratic costs (or productivities).
} 
70 percent of the variation in price dispersion across goods, although it comes at the cost of a slight overprediction of the average price dispersion. Notably, it is the heterogeneity in distribution costs that drives this improvement; without distribution costs, the sectoral model can generate only 26 percent of the variation (and 95 percent of the average).

In sum, international trade costs and local distribution costs can account for the average price dispersion for a basket of goods fully and generate 70 percent of the differences in price dispersion across goods within the basket. While tradability of goods is important in explaining the average market segmentation for the entire basket of goods, distribution costs are important in explaining why, within the basket, some goods show more price dispersion than others.

The broad conclusion that tradability of goods and use of non-traded inputs is important in explaining differences in cross-country price dispersion across goods is consistent with the findings of Crucini et al. (2005). However, like most of the literature on LOOP deviations, they use a reduced form model to carry out their analysis. Anderson and Wincoop (2004) and Gorodnichenko and Tesar (2009) have emphasized the need for a structural approach to study relative price deviations. The reduced form specification in Crucini et al. (2005) does not allow them to asses which dimension of tradability - trade costs or elasticity of substitution, is more important in driving price dispersion. The structural approach used in this paper allows us to do so. I find that the elasticity of substitution is the key parameter driving the variation in price dispersion across goods in the one-sector EK model. The onesector EK model, featuring trade costs as the only source of LOOP deviations, can generate average price dispersion broadly consistent with the data but not the variation. Changing the magnitude of trade costs, keeping the elasticity of substitution unchanged, cannot help to match the variation in price dispersion. On the other hand, elasticity of substitution can be chosen to match the moments of price dispersion. Choosing the elasticity of substitution to match the average price dispersion, exactly, results in a value of 5.5, which is at the lower end of the range of values estimated by EK. Additionally, the elasticity of substitution chosen to match the variation in price dispersion is significantly smaller than the lower bound of the range of values estimated by EK.

The lower estimates of the elasticity of substitution imply much larger gains from 
trade, and are supported by recent studies that use micro data on prices. Simonovska and Waugh (2010) show that the EK estimate is biased upwards due to a small sample bias and that correcting for this bias results in an estimate as low as 2.5. Giri, Yi and Yilmazkuday (2011) estimate trade elasticity for 21 manufacturing sectors and find that it ranges from a minimum of 3.1 to a maximum of 9 with an average of 4.6. However, the multi-sector model with distribution costs, using the benchmark value of the elasticity of substitution which is close to the preferred EK estimate, does very well in accounting for both moments of good-by-good price dispersion. Therefore, micro data on retail prices certainly raise the question of what is the right estimate of the elasticity of substitution.

This paper contributes to the emerging literature on structural models of international relative prices. Although some recent work has used structural models to study the effect of bilateral trade costs on the time-series behavior of bilateral relative prices - Atkeson and Burstein (2008), Ghironi and Melitz (2005), and Betts and Kehoe (2001) for example - the ability of a model of geography to contribute to an account of cross-sectional price dispersion has not been formally investigated. Similarly, the literature has investigated the role of distribution costs in explaining the time series properties of relative prices - Crucini and Shintani (2008) and Burstein et al. (2003) - and not the cross-sectional properties.

The paper is closest in spirit to Crucini and Yilmazkuday (2009), who develop a model of international cities, with complete specialization, to account for intra as well inter-national behavior of LOOP deviations. Importantly, they do not use trade flows in their estimation methodology whereas I estimate trade costs and solve the model by matching the trade volumes observed in the data. This allows me to assess whether a model that is consistent with observed trade flows can account for observed dispersion in prices.

The next section discusses the micro price data. In section 3, I start with the version of the model that abstracts from distribution costs and discuss its calibration. This is followed by results in section 4 . The role of elasticity of substitution and trade costs in driving price dispersion is discussed in section 5. In section 6, I present the model with distribution costs, discuss the calibration and the data on distribution costs. The results follow in the next section. Finally, the multi-sector framework is explained in section 8 . The last section concludes. 


\section{Measurement of LOOP Deviations}

The price data complied by Crucini et al. (2005) comes from four Eurostat surveys of retail prices in the capital cities of EU countries for each of the years 1975, 1980, 1985 and 1990. ${ }^{6}$ Across the surveys, the goods maintain a high degree of comparability across both location and time. The retail price of a good in a given country is the average of surveyed prices across different sales points within the capital city of that country. Furthermore, the authors remove the effect of different value added tax (VAT) rates across countries from the retail prices. In total, there are 13 countries in the sample - Austria, Belgium, Denmark, France, Germany, Greece, Ireland, Italy, Luxembourg, Netherlands, Portugal, Spain and United Kingdom. However, the 1975 survey covers nine EU countries. Greece, Portugal, and Spain were added in 1980. Austria was added in 1985. More detail on the data is provided in Appendix A.

Table 1: Good-by-Good Price Dispersion in Data

\begin{tabular}{lrrrrr}
\hline \hline & 1975 & 1980 & 1985 & 1990 & Avg. \\
\hline Avg. & 0.2290 & 0.2941 & 0.3024 & 0.2855 & 0.2778 \\
Max & 0.7496 & 0.7751 & 0.8189 & 0.8319 & 0.7939 \\
Min & 0.0227 & 0.0784 & 0.0672 & 0.0458 & 0.0535 \\
StDev & 0.1041 & 0.1225 & 0.1293 & 0.1304 & 0.1216 \\
\hline \hline
\end{tabular}

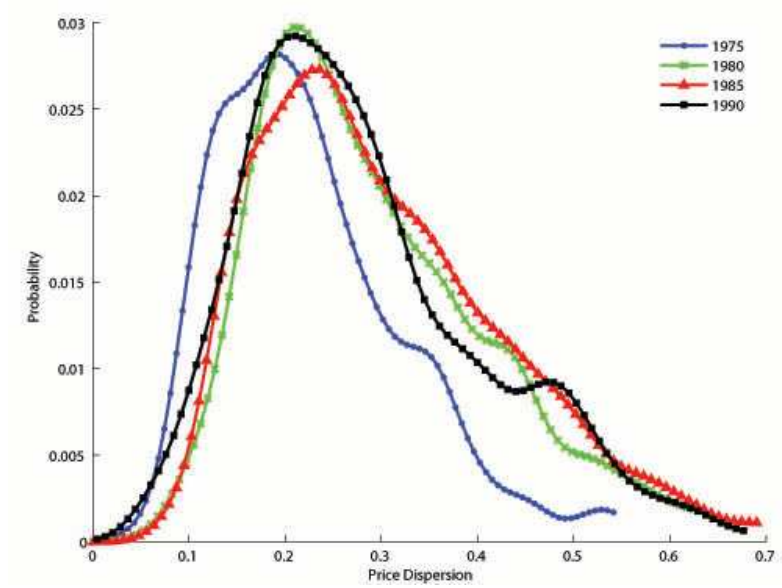

Figure 1: Empirical Distribution of $\operatorname{Var}\left(Q_{i}(x) \mid x\right)^{1 / 2}$ in the Data

Denote retail price of good $x$ in country $i$ (expressed in a common currency) by $P_{i}(x)$. The deviation from LOOP for good $x$ in country $i$ is $Q_{i}(x)=\log P_{i}(x)-\sum_{j=1}^{N} \log P_{j}(x) / N$,

\footnotetext{
${ }^{6}$ The data can be downloaded from http://www.aeaweb.org/articles.php?doi=10.1257/0002828054201332
} 
where $N$ is the number of countries. This captures the international relative price of a good in a country. Then standard deviation of $Q_{i}(x)$ across countries, given by $\sigma(x)=$ $\operatorname{Var}\left(Q_{i}(x) \mid x\right)^{1 / 2}$, captures the variation in the international relative price of a good across countries, and therefore it is the measure of price dispersion for a good. The authors also call this "good-by-good price dispersion". I focus on two measures of good-by-good price dispersion: (i) the average price dispersion across all goods (average of $\sigma(x)$ across goods) and (ii) the degree to which price dispersion varies across goods (standard deviation of $\sigma(x)$ across goods). The first measure provides an estimate of market segmentation for a basket of a large variety of goods. The second moment shows that within this basket there are some goods for which markets are not segmented at all and some others for which the degree of market segmentation is much higher than that reflected by the first moment.

The first row of Table 1 shows the average good-by-good price dispersion for each of the four years, and in the final column, the average of this measure over the four years. The average (Avg.) good-by-good price dispersion is about 28 percent over the four years. 1975 shows the smallest average price dispersion. However, it has remained quite stable for the other three years. The jump in price dispersion between 1975 and 1980 is argued to be due to a smaller sample of countries in the 1975 survey (9 out of the 13 countries). The same feature emerges in the standard deviation (StDev) of good-by-good price dispersion. Averaged over the four years, the standard deviation is 0.12 . The difference between minimum and maximum price dispersion shows that the variation in price dispersion across goods is quite large - ranging from a minimum of 2 percent to a maximum of 83 percent across the four years. Figure 1 depicts the kernel density of good-by-good price dispersion (reproduced from Crucini et al. (2005)) for the four years. The figure also reveals that the distribution of price dispersion has been very stable over time, which is why I focus on averages over the four years.

\section{Ricardian Trade Model}

To clearly explain the mechanism through which tradability, which is determined by trade costs and the elasticity of substitution, causes dispersion in prices of goods across countries I start with a version of the model that abstracts from distribution costs. Consider 
a world with $N$ countries. Country $i(i=1, \ldots, N)$ has $L_{i}$ consumers and each consumer has 1 unit of labor, which is supplied inelastically (all variables are expressed in per capita terms) and $k_{i}$ units of capital. A version of the EK model with capital was also used in Waugh (2009). Each country produces a continuum of base goods, indexed on the unit interval. Base good $x, x \in[0,1]$, in country $i$ is produced using a Cobb-Douglas technology

$$
m_{i}(x)=z_{i}(x)^{-\theta}\left[k_{i}(x)^{\alpha} l_{i}(x)^{1-\alpha}\right]^{\beta} c_{i}(x)^{1-\beta},
$$

where $k_{i}(x), l_{i}(x)$ and $c_{i}(x)$ are the amounts of capital, labor and intermediate composite, respectively, used to produce base good $x$ in country $i$. Following Alvarez and Lucas (2007) $z_{i}(x)$ denotes the inverse of the efficiency of country $i$ in producing good $x$. In other words $z_{i}(x)$ is an idiosyncratic "cost". It is assumed to be a random draw from a country-specific density $f_{i}=\exp \left(\lambda_{i}\right)$. The random cost draws are independent across goods, and the distributions are independent across countries. Further, these draws are amplified in percentage terms by the parameter $\theta$. A larger $\theta$ represents a larger variance in costs of (producing) individual goods. $\lambda_{i}$ determines country $i$ 's absolute advantage in producing any good $x$ whereas $\theta$ controls the degree of comparative advantage.

Countries trade base goods. In each country there is a representative importing firm that buys each base good $x$ at the lowest price. Let $\bar{m}_{i}(x)$ be the amount of base good $x$ that the importing firm in country $i$ buys. Base goods are then combined in country $i$ to produce an intermediate composite, $c_{i}$. This composite is a Spence-Dixit-Stiglitz (SDS) aggregator, with an elasticity of substitution, $\eta$, between goods:

$$
c_{i}=\left[\int_{0}^{\infty} \bar{m}_{i}(z)^{1-\frac{1}{\eta}} f(z) d z\right]^{\frac{\eta}{\eta-1}} .
$$

Here each good, $x$, is identified by its cost draw, $z$, and $f(z)$ is the joint distribution of cost draws $\left(\left(z_{1}(x), \ldots, z_{N}(x)\right)\right)$, over countries. A representative consumer in every country $i$ consumes a non-traded final good, $y_{i}$. The final good is produced with labor, $l_{y i}$, capital, $k_{y i}$, and intermediate composite, $c_{y i}$, as the inputs using Cobb-Douglas technology given by

$$
y_{i}=\left[k_{y i}^{\alpha} l_{y i}^{1-\alpha}\right]^{\rho} c_{y i}^{1-\rho}
$$

Finally, market clearing for the three inputs - intermediate composite, labor and capital - 
implies that

$$
\int_{0}^{1} c_{i}(x) d x+c_{y i} \leq c_{i} \quad, \quad \int_{0}^{1} l_{i}(x) d x+l_{y i} \leq 1 \quad, \quad \int_{0}^{1} k_{i}(x) d x+k_{y i} \leq k_{i} \quad .
$$

Let $c_{m i}=\int_{0}^{1} c_{i}(x) d x$ denote the units of the intermediate composite used in the base good sector, $l_{m i}=\int_{0}^{1} l_{i}(x) d x$ denote the share of base goods sector in the labor force, and $k_{m i}=$ $\int_{0}^{1} k_{i}(x) d x$ denote the units of capital used in the base good sector.

The object of interest in this baseline model is the price of an individual base good. Profit maximization in the two sectors - base goods and final good - implies that the return to capital in country $i$ is $r_{i}=(\alpha /(1-\alpha)) w_{i} k_{i}^{-1}$, where $w_{i}$ is the wage. Then, the domestic cost of producing base good $x$ in country $i$ is $B z_{i}(x)^{\theta} w_{i}^{\beta} p_{c i}^{1-\beta} k_{i}^{-\alpha \beta}$, where $B=\beta^{-\beta}(1-$ $\beta)^{(\beta-1)} \alpha^{-\alpha \beta}(1-\alpha)^{\beta(\alpha-1)}(\alpha /(1-\alpha))^{\alpha \beta} \cdot p_{c i}$ is the price of intermediate composite in country $i$

$$
p_{c i}=\left[\int_{0}^{\infty} \bar{p}_{m i}(z)^{1-\eta} f(z) d z\right]^{\frac{1}{1-\eta}},
$$

where $\bar{p}_{m i}(z)$ is the price of the base good characterized by productivity level $z$ in country $i$. The importing firm in each country buys each good, $x$, from the lowest cost supplier of that good. However, to deliver 1 unit of a base good from country $j$ to country $i$, country $j$ must produce $\tau_{i j}$ units of the good. Due to geographic and other barriers to trade, $\tau_{i j}>1$ for $i \neq j$, and $\tau_{i i}=1$ for all $i$. This is the standard "iceberg assumption" a la Samuelson. Furthermore, imposing the triangle inequality implies that $\tau_{i j} \leq \tau_{i k} \tau_{k j}$ for any three countries $i, k$ and $j$. Therefore, the price of $\operatorname{good} x$ in country $i$ is given by:

$$
\bar{p}_{m i}(x)=B \min _{j}\left[w_{j}^{\beta} p_{c j}^{1-\beta} k_{j}^{-\alpha \beta} \tau_{i j} z_{j}(x)^{\theta}\right] .
$$

In the absence of distribution costs, this is the retail price of good $x$.

\subsection{Price Dispersion}

Eq. (3.1) brings out the source(s) of $(i)$ price dispersion for a given good, and (ii) variation in price dispersion across goods. The source of dispersion in the price of a good is trade cost. If trade were costless, the country with lowest unit cost of production for a good would supply the good to all other countries. This would hold for all goods, and as a result all goods would show zero price dispersion. This would also be the case if trade costs were 
identical for all trading partners. Given positive trade costs, the variation in the degree of price dispersion across goods is driven by $\theta$.

To understand the role of the two sources of price dispersion transparently consider a world with four countries - $i=\{1,2,3,4\}$ - and three goods - $x=\{A, B, C\}$. Let $W_{i}=$ $B w_{i}^{\beta} p_{c i}^{1-\beta} k_{i}^{-\alpha \beta}$ be the factor cost in country $i$, and $\tau_{i j}=\left(1+\bar{\tau}_{i j}\right)$ where $\bar{\tau}_{i j}>0$. Given the triangle inequality on trade costs, for a given good there can be at most two exporters in a world of four countries. Suppose the random cost draws are such that good $A$ is supplied by a single exporter to all countries, good $B$ is supplied by two exporters to all countries, and good $C$ is not traded. Recall that the deviation from LOOP for good $x$ in country $i$ is $Q_{i}(x)=$ $\log P_{i}(x)-\sum_{j=1}^{N} \log P_{j}(x) / N$ which can be rewritten as $Q_{i}(x)=\frac{1}{N} \sum_{j=1}^{N} \log \left(P_{i}(x) / P_{j}(x)\right)$. This is nothing but an average of the $N$ (logarithm) bilateral relative prices for a good.

Suppose the single supplier for good $A$ is country 4 . Then bilateral relative prices for good $A$ for country $i$ are given by

$$
\frac{P_{i}(A)}{P_{j}(A)}= \begin{cases}\frac{1+\bar{\tau}_{i 4}}{1+\bar{\tau}_{j 4}} & \text { when } j \neq i \\ 1 & \text { when } j=i .\end{cases}
$$

Thus the deviation from the LOOP for good $A$ for country $i$ depends on its trade costs from the only supplier relative to trade cost of country $j$ from the only supplier. On the other hand, for good $C$, which is not traded, the relative costs of production are the only source of heterogeneity in LOOP deviations.

$$
\frac{P_{i}(C)}{P_{j}(C)}= \begin{cases}\frac{W_{i}}{W_{j}}\left(\frac{z_{i}(C)}{z_{j}(C)}\right)^{\theta} & \text { when } j \neq i \\ 1 & \text { when } j=i\end{cases}
$$

With respect to good $B$, let us assume that country 1 buys it from country 4 , country 2 buys it from country 3 , and countries 3 and 4 buy it from their domestic producers. The matrix of bilateral relative prices for good $B$ (elements of row $i$ give price of good $B$ in country $i$ relative to prices in other countries) is

$$
\left[\begin{array}{cccc}
1 & \frac{W_{4}}{W_{3}}\left(\frac{z_{4}(B)}{z_{3}(B)}\right)^{\theta}\left(\frac{1+\bar{\tau}_{14}}{1+\bar{\tau}_{23}}\right) & \frac{W_{4}}{W_{3}}\left(\frac{z_{4}(B)}{z_{3}(B)}\right)^{\theta}\left(1+\bar{\tau}_{14}\right) & \left(1+\bar{\tau}_{14}\right) \\
\frac{W_{3}}{W_{4}}\left(\frac{z_{3}(B)}{z_{4}(B)}\right)^{\theta}\left(\frac{1+\bar{\tau}_{23}}{1+\bar{\tau}_{14}}\right) & 1 & \left(1+\bar{\tau}_{23}\right) & \frac{W_{3}}{W_{4}}\left(\frac{z_{3}(B)}{z_{4}(B)}\right)^{\theta}\left(1+\bar{\tau}_{23}\right) \\
\frac{W_{3}}{W_{4}}\left(\frac{z_{3}(B)}{z_{4}(B)}\right)^{\theta}\left(\frac{1}{1+\bar{\tau}_{14}}\right) & \left(\frac{1}{1+\bar{\tau}_{23}}\right) & 1 & \frac{W_{3}}{W_{4}}\left(\frac{z_{3}(B)}{z_{4}(B)}\right)^{\theta} \\
\left(\frac{1}{1+\bar{\tau}_{14}}\right) & \frac{W_{4}}{W_{3}}\left(\frac{z_{4}(B)}{z_{3}(B)}\right)^{\theta}\left(\frac{1}{1+\bar{\tau}_{23}}\right) & \frac{W_{4}}{W_{3}}\left(\frac{z_{4}(B)}{z_{3}(B)}\right)^{\theta} & 1
\end{array}\right] .
$$


Notice, as compared to good $A$, for good $B$ the presence of more suppliers brings an additional source of heterogeneity in LOOP deviations - the relative cost of production, which has a country specific component (ratio of $W \mathrm{~s}$ ) and a good specific component (ratio of $z \mathrm{~s}$ ). Therefore, relative to good $A$, good $B$ will exhibit higher dispersion in $Q_{\mathrm{s}}$ across countries and hence a higher $\sigma$. In the case of good $C$, because the trade costs are very high, there are no opportunities for arbitrage which implies that relative to good $B$, good $C$ will have a higher dispersion in $Q \mathrm{~s}$, and therefore a higher $\sigma$.

In the more general settings of the model goods of type $A$, with a single global supplier, and goods of type $C$, with as many suppliers as buyers, represent the lower and upper bound on cross-country price dispersion, respectively. Goods of type $B$, with number of suppliers between 1 and $N$, will exhibit price dispersion within these bounds.

What is the effect of change in trade costs on the average price dispersion (average of $\sigma(A), \sigma(B)$ and $\sigma(C)$ ) and the variation in price dispersion (dispersion across $\sigma(A), \sigma(B)$ and $\sigma(C))$ ?

For trade costs $\bar{\tau} \neq \bar{\tau}^{\prime}$, define $R=(1+\bar{\tau}) /\left(1+\bar{\tau}^{\prime}\right)$. Suppose trade costs are changed by the same factor, $\kappa$ (lower (higher) $\kappa$ means lower (higher) trade costs), then $R$ can be written as $R=1+\left(\bar{\tau}-\bar{\tau}^{\prime}\right) /\left((1 / \kappa)+\bar{\tau}^{\prime}\right)$. Then, as $\kappa$ becomes smaller, i.e. all trade costs fall, $R \rightarrow 1$. On the other hand, as $\kappa$ increases $R \rightarrow \bar{\tau} / \bar{\tau}^{\prime}$.

Now, consider a reduction in trade costs, i.e. $\kappa$ falls. This would make the ratio of trade costs, $R$, and $1 /(1+\bar{\tau})$ and $(1+\bar{\tau})$ move closer to one. Then, for goods $A$ and $B$, the deviations from LOOP, $Q_{i} \mathrm{~s}$, will also move closer one, and hence result in lower $\sigma \mathrm{s}$. For good $C$, the reduction in trade costs will make arbitrage possible, and as result some of these goods will now become traded, which means $\sigma(C)$ will decrease. Lower $\sigma$ s for each type of good implies that the average of the $\sigma$ s across goods is also lower. Furthermore, a reduction in trade costs shifts goods out of type $C$ into goods of type $B$ and goods of type $B$ into goods of type $A$. Thus, the distribution of $\sigma$ s across goods will become narrower. As a result there is less dispersion in $\sigma \mathrm{s}$ as trade costs decline. An increase in trade costs works in the opposite manner - as trade costs increase, more and more goods are not traded, i.e. goods shift from type $A$ to $B$ to $C$. This results in an increase in the average of $\sigma$ s as well as in the dispersion in $\sigma$ s across goods. 
To understand the role of $\theta$, consider a very small value of $\theta$. First, for goods of type $B$ and type $C$ the ratio of costs of production become smaller, which implies that $Q$ s become smaller. Furthermore, since the good-specific part of costs of production becomes smaller relative to the factor costs component, the heterogeneity in $Q_{\mathrm{s}}$ reduces, which results in lower $\sigma$ s. Second, a small $\theta$, by making the good-specific part of production costs less important, implies that comparative advantage is largely determined by factor costs. Thus, countries with lowest factor costs will supply most goods to the rest of the world. As a result the number of suppliers per good will fall, resulting in more goods of type $A$ relative to type $B$ and $C$. Combining the two effects implies that the average price dispersion, as well as the variation in price dispersion across goods, will fall. Analogously, a large $\theta$, will result in higher average price dispersion and higher variation in price dispersion.

In a multi-sector model (discussed later in section 8), where trade costs and $\lambda \mathrm{s}$ are sector-specific, (potentially) there will be greater heterogeneity in trade costs and costs of production across goods of different sectors. This will result in greater heterogeneity, across sectors, in the distribution of goods into type A, B and C, which in turn will cause good-bygood price dispersion to be larger.

\subsection{Model Solution and Simulation of Prices}

The methodology to solve the model follows Waugh (2009). In order to obtain the prices of individual base goods, I solve for the vector of wages, w, and the vector of prices of the intermediate composite, $\mathbf{p}_{\mathbf{c}}$, and calibrate the vector of productivity parameters, $\boldsymbol{\lambda}$, given the matrix of estimated trade costs, $\boldsymbol{\tau}$, and the vectors of labor and capital endowments - $\mathbf{L}$ and $\mathbf{k}$, respectively. I start by discussing the estimation of trade costs.

Let $X_{i}$ be the per capita expenditure of country $i$ on tradable goods. Define $D_{i j}$ as the share of country $i$ 's per capita spending on tradables that is spent on goods from country $j$. For country $j$ to supply good $x$ to country $i, j$ must be the lowest price seller of good $x$ to i. Then,

$$
D_{i j}=(A B)^{-1 / \theta}\left(\frac{w_{j}^{\beta} p_{c j}^{1-\beta} k_{j}^{-\alpha \beta} \tau_{i j}}{p_{c i}}\right)^{-1 / \theta} \lambda_{j},
$$

and $\sum_{j=1}^{N} D_{i j}=1 .^{7}$ Eq. (3.2) implies that the share of country $j$ in country $i$ 's total

\footnotetext{
${ }^{7}$ See Alvarez and Lucas (2007) for derivation.
} 
expenditure on tradables, normalized by country $i$ 's share in its own total expenditure on tradables, is given by:

$$
\frac{D_{i j}}{D_{i i}}=\frac{\left(w_{j}^{\beta} p_{c j}^{1-\beta} k_{j}^{-\alpha \beta} \tau_{i j}\right)^{-1 / \theta} \lambda_{j}}{\left(w_{i}^{\beta} p_{c i}^{1-\beta} k_{i}^{-\alpha \beta}\right)^{-1 / \theta} \lambda_{i}} .
$$

Let $\Omega_{i}=\left(w_{i}^{\beta} p_{c i}^{1-\beta} k_{i}^{-\alpha \beta}\right)^{-1 / \theta} \lambda_{i}$, and $S_{i}=\ln \left(\Omega_{i}\right)$. This implies that

$$
\ln \left(\frac{D_{i j}}{D_{i i}}\right)=S_{j}-S_{i}-\frac{1}{\theta} \ln \tau_{i j}
$$

The left-hand side of this equation is calculated from data on bilateral trade and gross output. The methodology used to calculate the left-hand side is explained in Appendix B. Trade costs are obtained by estimating Eq. (3.3). Since $\tau_{i j}$ is not observable, following EK, I proxy trade barriers by distance, language, border and membership of free trade regions. Specifically,

$$
\ln \tau_{i j}=d i s t_{I}+b r d r+l a n g+t b l k_{M}+d e s t_{i}+\epsilon_{i j}
$$

where $\operatorname{dist}_{I}(I=1, \ldots, 6)$ is the effect of distance between $i$ and $j$ lying in the $I$ th interval, $b r d r$ is the effect of $i$ and $j$ sharing a border, lang is the effect of $i$ and $j$ sharing a language, $\operatorname{tblk}_{M}(M=1,2)$ is the effect of $i$ and $j$ belonging to trading area $M$, and dest $_{i}(i=1, \ldots, N)$ is a destination effect. The error term $\epsilon_{i j}$ captures trade barriers due to all other factors, and is orthogonal to the regressors. The errors are assumed to be normally distributed with mean zero and variance, $\sigma_{\epsilon}$. The six distance intervals (in miles) are: $[0,375) ;[375,750) ;[750,1500) ;[1500,3000) ;[3000,6000)$ and $[6000$, maximum]. The two trading areas are the European Union (EU) and the North-American Free Trade Agreement (NAFTA) area. $S_{i}$ is captured as the coefficient on source-country dummies.

Eq. (3.1) implies that the price of the intermediate composite is given by ${ }^{8}$

$$
p_{c i}=A B\left(\sum_{j=1}^{N}\left(w_{j}^{\beta} p_{c j}^{1-\beta} k_{j}^{-\alpha \beta} \tau_{i j}\right)^{-1 / \theta} \lambda_{j}\right)^{-\theta}
$$

which, given the expression for $S_{i}$ s, can be rewritten as

$$
p_{c i}=A B\left(\sum_{j=1}^{N} e^{S_{j}} \tau_{i j}^{-1 / \theta}\right)^{-\theta}
$$

\footnotetext{
${ }^{8}$ See Alvarez and Lucas (2007) for the derivation.
} 
where $A=\left(\int_{0}^{\infty} h^{\theta(1-\eta)} e^{-h} d h\right)^{\frac{1}{1-\eta}} \cdot 9$ The vector of wages is determined by imposing balanced trade, which, including how much a country buys from itself, is given by

$$
\sum_{j=1}^{N} L_{j} X_{j} D_{j i}=L_{i} X_{i}
$$

In the base goods sector $L_{i} w_{i} l_{m i}=\beta(1-\alpha) \sum_{j=1}^{N} L_{j} X_{j} D_{j i}=\beta(1-\alpha) L_{i} X_{i}$. Since $l_{m i}=$ $1-l_{y i}=1-\rho, \forall i$, the balanced trade condition can be written as

$$
\sum_{j=1}^{N} L_{j} w_{j} D_{j i}=L_{i} w_{i}
$$

Given the bilateral expenditure shares computed from the the data, and labor and capital for each country obtained from the data, Eq. (3.7) is used to solve for the equilibrium wage vector. Lastly, the estimate of $S_{i}$ is used to extract the value of $\lambda_{i}$ in the following manner:

$$
\lambda_{i}=\frac{e^{S_{i}}}{\left(w_{i}^{\beta} p_{c i}^{1-\beta} k_{i}^{-\alpha \beta}\right)^{-1 / \theta}} .
$$

After estimating $S_{i} \mathrm{~s}$ and $\tau_{i j}$ s from Eq. (3.3) I solve for equilibrium $p_{c i}$ and $w_{i}$, and calibrate $\lambda_{i}$ by using Eq. (3.6), Eq. (3.7) and Eq. (3.8). By computing $\boldsymbol{\lambda}$ and $\boldsymbol{\tau}$ as functions of bilateral trade shares, I calibrate the sources of price dispersion from data on trade flows. This imposes the discipline on the model needed to evaluate whether the degree of market segmentation implied by flows of goods across borders can explain the deviations from the LOOP in prices of individual goods.

Having obtained $w_{i}, p_{c i}, \lambda_{i}, \tau_{i j}$, and $k_{i}$, I simulate the model by drawing idiosyncratic costs for goods $\left(z_{i}(x)\right)$ for each country from the country-specific distribution $\left(\exp \left(\lambda_{i}\right)\right)$, and then use Eq. (3.1) to compute the prices of the goods. The deviation from LOOP for good $x$ in country $i$ is computed as

$$
Q_{m i}(x)=\log p_{m i}(x)-\frac{\sum_{j=1}^{N} \log p_{m j}(x)}{N} .
$$

Dispersion in the price a good is given by the cross-country dispersion in the LOOP deviations for the good $x$, denoted by $\sigma(x)=\operatorname{Var}\left(Q_{m i}(x) \mid x\right)^{1 / 2}$. Then, I compute $(i)$ the average of

\footnotetext{
${ }^{9}$ The integral in brackets is the Gamma function $\Gamma(\xi)$ evaluated at $\xi=1+\theta(1-\eta)$ Convergence of this integral requires that $1+\theta(1-\eta)>0$, which I assume holds throughout this paper.
} 
$\sigma(x)$ over all goods to get the average price dispersion, and (ii) the standard deviation of $\sigma(x)$ across all goods to get the variation in price dispersion across goods. I carry out 100 simulations and assume that the number of goods is 1500. All reported statistics are averages over the simulations. ${ }^{10}$

\subsection{Calibration}

There are 22 OECD countries in the sample. ${ }^{11}$ In addition to the $13 \mathrm{EU}$ countries included in Crucini et al. (2005), I include nine other countries. Using only the $13 \mathrm{EU}$ countries will result in underestimation of total trade volume and consequently affect the estimates of trade costs. Therefore, I choose a broader set of countries to account for as large a share of total trade as possible, at the same time ensuring that the chosen countries have similar levels of per capita GDP as those considered in Crucini et al. (2005). The model is calibrated to the year 1996.

The traded goods sector includes agriculture, hunting, forestry and fishing, mining and quarying, and manufacturing. All other sectors form the final good sector. The parameter $\beta$ is calibrated as the share of value added in gross output of the traded goods sector. Details of the data and the methodology are provided in Appendix B. For the sample of countries $\beta$ is 0.36. $\alpha$ is the share of capital in GDP. Gollin (2002) finds that the share of labor in value added for a wide cross-section of countries is around $2 / 3$, which implies that $\alpha$ is 0.33 . $\rho$ is the share of value added in gross output of the final good sector. Since the value of the output of the final good sector is the GDP of a country, $\rho$ is calibrated as one minus the share of traded goods sector in GDP. I find that the share of traded goods sector in GDP is 0.25 which implies that $\rho$ is 0.75 . Following Alvarez and Lucas (2007), $\theta$, which controls the variability of the national idiosyncratic component of productivity, is 0.15 , which lies well within the range of values estimated by EK for the OECD countries (values range

\footnotetext{
${ }^{10}$ Even though the distribution of equilibrium prices in country $i$ is a Weibull, the density function of $Q_{m i}$ is not tractable because no results (not even approximations) have been known for sums of Weibull random variables (see Nadarajah (2008)). As a result there is no analytical expression for the distribution of $\sigma(x)$.

${ }^{11}$ Australia, Austria, Belgium, Canada, Denmark, Finland, France, Germany, Greece, Ireland, Italy, Japan, Mexico, Netherlands, New Zealand, Norway, Portugal, Spain, Sweden, Switzerland, United Kingdom, United States.
} 
from a minimum of 0.08 to a maximum of 0.28 ). In the following sections I investigate the implications of different values of $\theta$ for the results of the model. $\eta$, which is the substitution parameter, is $2 .^{12}$ The labor force vector $\mathbf{L}=\left(L_{1}, \ldots, L_{n}\right)$ and the vector of capital-labor ratios $\mathbf{k}=\left(k_{1}, \ldots, k_{n}\right)$ are taken from the data in Caselli $(2005) .{ }^{13}$ Table 15 , in Appendix $\mathrm{C}$, summarizes the parameterization of the Ricardian model.

Table 2 reports the estimated coefficients for geographic barriers, the corresponding standard errors and the implied effect on cost relative to home sales. ${ }^{14}$ The costs imposed by trade barriers are comparable to the costs obtained by EK, both quantitatively and qualitatively. Since I include all traded goods - agricultural goods, fuels and mining goods, and manufacturing goods - in computing bilateral trade shares, whereas EK consider only manufacturing goods, I get slightly higher estimates of costs imposed by trade barriers.

Table 2: Geographic Barriers

\begin{tabular}{llrrr}
\hline \hline Variable & Denoted by & Coefficient & Std. Error & \% Effect on Cost \\
\hline Distance [0,375) & $-\frac{1}{\theta}$ dist $_{1}$ & -3.76 & 0.16 & 75.85 \\
Distance [375,750) & $-\frac{1}{\theta}$ dist $_{2}$ & -3.91 & 0.13 & 79.80 \\
Distance [750,1500) & $-\frac{1}{\theta}$ dist $_{3}$ & -4.25 & 0.12 & 89.09 \\
Distance [1500,3000) & $-\frac{1}{\theta}$ dist $_{4}$ & -4.47 & 0.17 & 95.43 \\
Distance [3000,6000) & $-\frac{1}{\theta}$ dist $_{5}$ & -6.26 & 0.08 & 155.67 \\
Distance [6000,maximum] & $-\frac{1}{\theta}$ dist $_{6}$ & -6.65 & 0.09 & 171.15 \\
Shared Border & $-\frac{1}{\theta}$ brdr & 0.65 & 0.13 & -9.34 \\
Shared Language & $-\frac{1}{\theta}$ lang & 0.30 & 0.10 & -4.41 \\
EU & $-\frac{1}{\theta}$ tblk & 0.19 & 0.14 & -2.88 \\
NAFTA & $-\frac{1}{\theta}$ tblk & -0.39 & 0.35 & 6.01 \\
\hline R-Square $=0.9221$ & Adj.R-Square $=0.9122$ & N Obs $=462$ & \\
\hline \hline
\end{tabular}

\section{Results: Ricardian Model}

Table 3 compares the model-generated good-by-good price dispersion with that observed in the data. Remarkably, this multi-country Ricardian model can account for 84 percent of the average good-by-good price dispersion observed in the data. However, with respect to the variation in good-by-good price dispersion, as measured by standard devia-

\footnotetext{
${ }^{12}$ Value of $\eta$ is important only for the convergence of the gamma function and it does not have any implications for the results of the model.

${ }^{13}$ I thank Michael E. Waugh for sharing this data with me.

${ }^{14}$ Destination effect coefficients are not reported for brevity. The coefficients and standard errors are similar to those reported by EK.
} 
tion, the model can generate 23 percent of the variation observed in the data. The empirical distribution of good-by-good price dispersion obtained from the model is shown in Figure 2.

Table 3: Good-by-Good Price Dispersion: Model Versus Data

\begin{tabular}{lrrr}
\hline \hline & Model & Data & Model as ratio of Data \\
\hline Avg. & 0.2334 & 0.2778 & 0.8402 \\
StDev & 0.0277 & 0.1216 & 0.2277 \\
\hline \hline
\end{tabular}

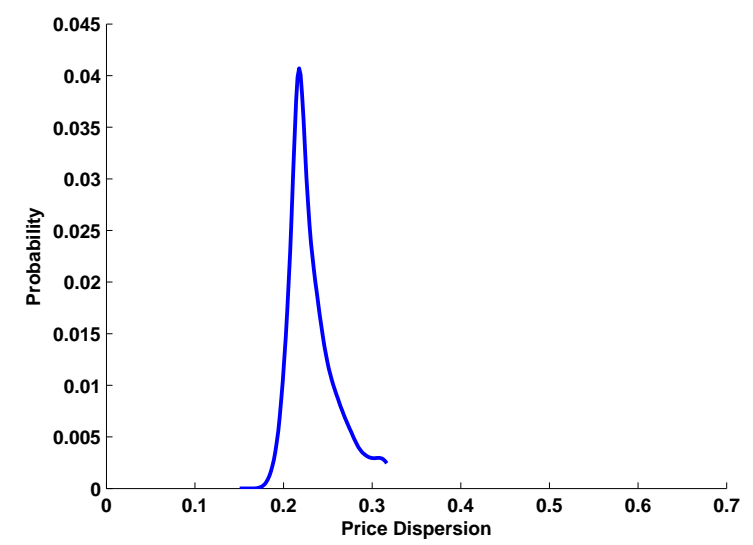

Figure 2: Distribution of $\operatorname{Var}\left(Q_{m i}(x) \mid x\right)^{1 / 2}$ : Ricardian Model

These results suggest that, for a basket of retail goods, the degree of goods' market segmentation implied by bilateral and asymmetric trade costs is consistent with the degree of segmentation implied by dispersion of LOOP deviations, but not large enough to account for the average price dispersion fully. Furthermore, given the estimated trade costs, the goodspecific heterogeneity in costs of production (or productivities) generated by the chosen value of $\theta$ and the parameterized distributions of the countries does a poor job of matching the variation in price dispersion across goods.

\section{Role of $\theta$ and Trade Costs}

The parameters of the model that control the heterogeneity in prices across goods are $\theta$ and the trade costs, $\tau_{i j} \mathrm{~s}$. In order to understand the results we have to examine the quantitative importance of each of these parameters in generating price dispersion.

\subsection{Role of $\theta$}

As explained earlier, $\theta$ governs the heterogeneity in costs (or idiosyncratic productivity) across goods. In other words, a given draw of $z$ has a much larger impact on the production 
cost of a base good if $\theta$ is large. Therefore, a large $\theta$ results in greater dispersion in costs of production of base goods across countries. Furthermore, the magnitude of trade costs (estimated in Eq. (3.3)) also depends on the value of $\theta$. A higher $\theta$ results in higher implied percentage effect on costs of selling goods to another country relative to selling goods at home. ${ }^{15}$

Table 4: Effect of $\theta$ on Good-by-Good Price Dispersion

\begin{tabular}{l|rr}
\hline \hline Value of $\theta$ & Avg. & StDev \\
\hline 0.08 & 0.1168 & 0.0080 \\
0.15 (benchmark) & 0.2334 & 0.0277 \\
0.28 & 0.4119 & 0.0553 \\
\hline \hline
\end{tabular}

Table 4 shows the effect of a change in value of $\theta$ on good-by-good price dispersion. The benchmark value (value used in the model) of $\theta$ is 0.15 . The other values considered are the upper and lower bounds of the range of values estimated by EK ( $\theta$ in this model is the inverse of that used in EK). The benchmark value lies between the two bounds. The results show the dual implications of changing the magnitude of $\theta$ : $(i)$ as explained earlier (in section 3.1), as $\theta$ increases the average good-by-good price dispersion, as well as the variation in price dispersion, increases because of the larger heterogeneity in unit costs, and (ii) because of the rise in the implied effect, on costs, of trade costs the increase in the average price dispersion and variation in price dispersion is reinforced.

Among the values of $\theta$ estimated by EK, their preferred value of $\theta=0.12$ (i.e. $\theta=8.28$ in the EK setup) is obtained using information on prices. The model implies the following relationship between trade volumes and price indices between two countries - $D_{i j} / D_{j j}=$ $\left(p_{c j} \tau_{i j} / p_{c i}\right)^{-1 / \theta}$. To compute the ratio of price indices $\left(p_{c j} / p_{c i}\right)$ for a trading pair, the authors compute ratio of retail prices (between trading pairs) of 50 manufactured products and take an average over those ratios. $\tau_{i j}$ is taken to be equal to the second-highest ratio of retail prices among the 50 products. $\theta$ is the method-of-moments estimator obtained from this structural relationship. This value of $\theta$, therefore, is consistent with average price differences across countries, given the trade volumes and trade costs, for a much smaller basket of goods. However, for $\theta=0.12$, the average price dispersion generated by the model is 0.19

\footnotetext{
$151 / \theta$ in this model is akin to the elasticity of substitution between goods in an armington model of trade or in a monopolistic competition model of trade.
} 
(explaining 68 percent of the average), whereas the standard deviation is 0.02 (explaining 16 percent of the variation).

What are the values of $\theta$ that would match the two moments of the price data? The results of Table 4 imply that one cannot pick a value of $\theta$ to match both the average price dispersion as well as the variation in price dispersion.

I find that with $\theta=0.18$, which is equivalent to 5.5 in the EK setup, the model can match the average price dispersion observed in the data. Simonovska and Waugh (2010) argue that the estimation methodology of EK, explained above, results in an overestimation of $\theta$. Since $D_{i j} / D_{j j}=\left(p_{c j} \tau_{i j} / p_{c i}\right)^{-1 / \theta}, 1 / \theta$ is the elasticity of bilateral trade volume with respect to bilateral trade frictions. Thus, small trade flows can be explained by either large trade frictions and small elasticity or by small trade frictions and large elasticity. Simonovska and Waugh (2010) show that the small sample of 50 products used to estimate $\theta$ in EK results in underestimation of trade costs, which leads to an overestimation of $\theta$. They find that correcting for this small sample bias results in a value as low as 2.5. Giri, Yi and Yilmazkuday (2011), using the retail price data of Crucini et al. (2005), estimate trade elasticities for 21 manufacturing sectors and find that $\theta$ ranges from a minimum of 3.1 to a maximum of 9 . Ignoring the sectoral dimension, they also find an aggregate $\theta$ of 2.5. Bernard, Eaton, Jensen and Kortum (2003) and Eaton, Kortum and Kramarz (2008), based on firm level data, find that $\theta$ lies in the range of 3.6 to 4.8, while Burstein and Vogel (2009), using data on skill intensity of trade find $\theta$ to be 4 . Donaldson (2009), studying the differences in prices of salt in India, finds a range of 3.8 to 5.2. The smallest value of $\theta$ in EK, based on wage data, is 3.6.

However, with $\theta=0.18$ the model explains 30 percent of the variation in price dispersion. To match the variation in price dispersion the model requires a $\theta$ of 0.58 , which is equivalent to 1.72 in the EK setup. This is much smaller than any of the estimates discussed above. But, as explained earlier, a higher $\theta$ results in higher average price dispersion, - the model overpredicts the average by a factor of 2.7 .

This finding that one needs much lower values of $\theta$ to match the moments of the distribution of good-by-good price dispersion is important because the value of $\theta$ is critical to understand the size of trade barriers, the response of trade flows to reduction in trade 
barriers and the welfare implications of trade; smaller values imply larger gains from trade.

\subsection{Role of Trade Costs}

In this section I examine the role of trade costs in driving good-by-good price dispersion. I start by evaluating the importance of asymmetry in trade costs. To do this, I carry out a counterfactual where trade costs are symmetric. This is done by excluding the destination effect from the functional form of trade cost (Eq. (3.4)) and then computing symmetric trade costs by re-estimating the gravity equation (Eq. (3.3)). Next, I assess the importance of the magnitude of trade costs by $(i)$ setting trade costs at half of the estimated levels, and $(i i)$ setting trade costs at twice of the estimated levels. In doing this, the degree of symmetry is not altered. In carrying out all the counterfactuals, the vector of $\lambda_{\mathrm{s}}$ is the same as that calibrated in the benchmark specification, and equilibrium wages, prices of intermediate composite and bilateral expenditure shares are solved for by using Eq. (3.7), Eq. (3.5) and Eq. (3.2).

Table 5: Role of Trade Costs

\begin{tabular}{l|rr}
\hline \hline & Avg. & StDev \\
\hline Benchmark Specification & 0.2334 & 0.0277 \\
Symmetric Trade Costs & 0.2155 & 0.0167 \\
Asymmetric Trade Costs - Half & 0.1526 & 0.020 \\
Asymmetric Trade Costs - Double & 0.3310 & 0.035 \\
\hline Data & 0.2778 & 0.1216 \\
\hline \hline
\end{tabular}

Table 5 reveals that the asymmetry in trade costs is important. The standard deviation generated with asymmetric trade costs is about 1.6 times larger than that generated by the specification with symmetric trade cost. The lack of asymmetry in trade costs reduces the heterogeneity in buyer-supplier pairs across goods, which reduces the variation in price dispersion across goods. The average price dispersion generated by the model is not greatly affected (it decreases slightly).

Rows four and five of Table 5 illustrate the effect of changing the magnitude of trade costs without altering the degree of asymmetry. Reducing trade costs to half of the benchmark (estimated) level causes a decline in both average price dispersion and variation in price dispersion. Lower trade costs increase the likelihood that the countries with the lowest production costs capture most foreign markets, and as a result reduces the number of 
suppliers per good. As explained earlier, this reduces both the average and the standard deviation of good-by-good price dispersion. Increasing trade costs to twice the estimated level increases both the average and the dispersion. The mechanism is the same as that for a decline in trade costs, but works in the other direction by making more goods non-traded.

Therefore, the correlation between good-by-good price dispersion and good-by-good dispersion in costs of production will be high for high levels of trade costs and low for low levels of trade costs. This is illustrated in Figures 3(a) and 3(b) for two cases - (i) trade costs are one-tenth of the benchmark level, and (ii) trade costs are five times the benchmark level. The correlation for the low trade-cost case is 22 percent, whereas that for the high trade-cost case is 97 percent. Table 6 shows the average price dispersion and the standard deviation of price dispersion for different levels of trade costs. It becomes clear that even for very high levels of trade costs, the variation in price dispersion generated by the model is no more than 35 percent of that observed in the data. Thus, even very high levels of bilateral and asymmetric trade costs cannot generate the heterogeneity in price dispersion observed in the data. Moreover, this comes at the cost of generating average price dispersion that is higher than that observed in the data, and making most goods non-traded.

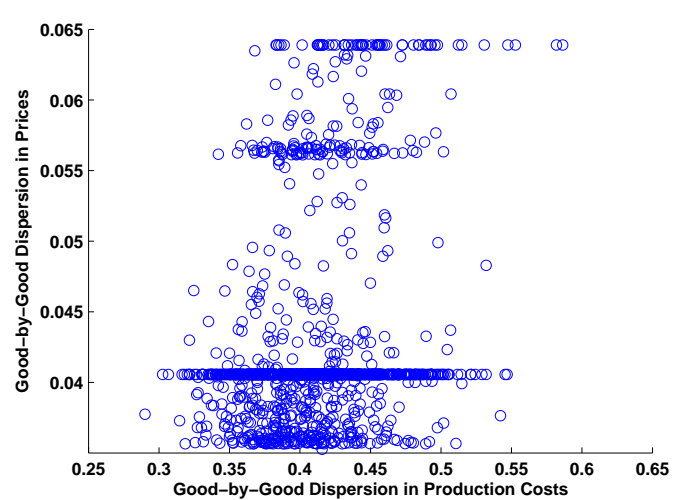

(a) Trade Costs: One-tenth of Benchmark Level

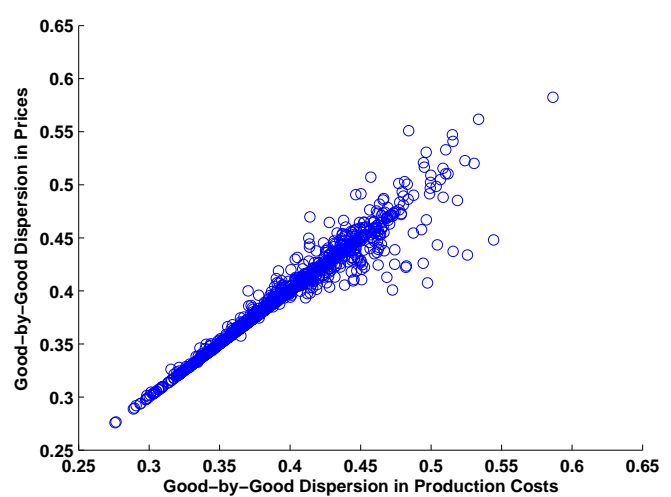

(b) Trade Costs: Five Times Benchmark Level

Figure 3: Magnitude of Trade Costs and Correlation Between Price Dispersion and Costs of Production

Table 6: Good-by-Good Price Dispersion for Different Levels of Trade Costs

\begin{tabular}{l|rr}
\hline \hline Trade Cost Level & Average & StDev \\
\hline 75 percent lower & 0.091 & 0.013 \\
25 percent lower & 0.201 & 0.025 \\
\hline Benchmark level & 0.233 & 0.028 \\
\hline 25 percent higher & 0.266 & 0.032 \\
\hline
\end{tabular}


Table 6: (continued)

\begin{tabular}{l|rr}
\hline \hline Trade Cost Level & Average & StDev \\
\hline 75 percent higher & 0.312 & 0.035 \\
100 percent higher & 0.331 & 0.035 \\
300 percent higher & 0.388 & 0.038 \\
400 percent higher & 0.391 & 0.040 \\
600 percent higher & 0.396 & 0.042 \\
\hline \hline
\end{tabular}

As a robustness check, I carry out the benchmark calibration by using a specification for trade costs advocated by Waugh (2009). The difference with respect to Eq. (3.4) is that instead of destination effect there is a source effect. Waugh (2009) argues that, for trade between rich and poor countries, the specification with destination effect generates counterfactual implications relative data on aggregate price of tradables. ${ }^{16}$ So, the new specification is given by

$$
\ln \tau_{i j}=d_{i s t_{I}}+b r d r+\operatorname{lang}+t b l k_{M}+s r c_{j}+\epsilon_{i j}
$$

where $s r c_{j}$ is the source effect or an exporter fixed effect. With respect to the goodness of fit, this specification performs as well as the benchmark specification, and in fact it has the same fitted values. ${ }^{17}$ With the exporter fixed effect, the model generates an average price dispersion of 0.2836 percent and a standard deviation of 0.02 . Thus, the model can match the average price dispersion observed in the data perfectly but generates less variation in price dispersion as compared to the model with importer fixed effect.

\section{Ricardian Trade Model with A Local Distribution Sector}

In this section, I develop a model of trade and retailing by extending the multi-country Ricardian trade model of EK to account for local costs of distribution. Now, base goods, besides being used to produce the intermediate composite, are also delivered to the consumer as retail goods. A retail good is produced by combining distribution services and a base good (whether produced domestically or imported). Distribution services and retail goods are not traded.

\footnotetext{
${ }^{16}$ To match both trade data and data on aggregate price of tradables, poor countries must face systematically higher costs of exporting than rich countries.

${ }^{17}$ As found by Waugh (2009), the estimated value of exporter fixed effect is the same as that of importer fixed effect. But now the interpretation is different.
} 
The production technology of base goods is unchanged. However, now the amount of base good $x$ bought by the importing firm, $\bar{m}_{i}(x)$, is divided into two parts:

$$
\bar{m}_{i}(x)=\bar{m}_{c i}(x)+\bar{m}_{q i}(x)
$$

$\bar{m}_{c i}(x)$ is used to produce the intermediate composite in country $i$, and $\bar{m}_{q i}(x)$ is bought by the retailer of good $x$ in country $i$. The production technology for intermediate composite good is unchanged, and therefore

$$
c_{i}=\left[\int_{0}^{\infty} \bar{m}_{c i}(z)^{1-\frac{1}{\eta}} f(z) d z\right]^{\frac{\eta}{\eta-1}} .
$$

The retailer of good $x$ combines $\bar{m}_{q i}(x)$ with distribution services to deliver the base good to the consumer in the form of a retail good. Output of retail good $x$ is denoted by $m_{q i}(x)$. Distribution services, $d_{i}$, are produced with labor, $l_{d i}$, capital, $k_{d i}$, and intermediate composite, $c_{d i}$, using Cobb-Douglas technology which is given by

$$
d_{i}=\left[k_{d i}^{\alpha} l_{d i}^{1-\alpha}\right]^{\delta} c_{d i}^{1-\delta}
$$

To deliver 1 unit of base good $x$ to the consumer, $\phi_{i}(x)$ units of distribution services are required,

$$
\phi_{i}(x)=\zeta_{i} u(x)^{\nu}
$$

where $\zeta_{i}$ denotes the units of distribution services required to deliver any good to the consumer in country $i$, and reflects country $i$ 's efficiency in distribution of goods, and $u$ is a random draw from a common density function $g=\exp (1)$. The draws are assumed to be independent across goods. For a given base good $x, u$ and $z$ (random cost draw for base good $x$ ) are also assumed to be independent.

Bringing 1 unit of a base good to the consumer requires a fixed proportion of distribution services. This assumption is made in the spirit that production and retailing are complements, and consumers consume them in fixed proportions. Erceg and Levin (1996), Burstein et al. (2003) and Corsetti and Dedola (2005) also adopt the same production structure for retail goods. However, I allow the units of distribution services used to deliver a unit of a good to vary across goods, as well as countries, whereas these studies do not. Furthermore, these studies, for simplicity, do not differentiate between nontradable consumption 
goods, which directly enter the agent's utility and nontraded distribution services, which are jointly consumed with traded goods. However, I make this distinction. This is necessary because the parameters $\nu$ and $\zeta_{i}$, which govern heterogeneity in the use of distribution services, are calibrated using the data on distribution margins and not from the data on all services.

Therefore, in addition to producing distribution services, each country also produces a homogeneous non-traded good. Production of the non-traded good also combines labor, $l_{s i}$, capital, $k_{s i}$, and the intermediate composite, $c_{s i}$, using a Cobb-Douglas technology:

$$
s_{i}=\left[k_{s i}^{\alpha} l_{s i}^{1-\alpha}\right]^{\gamma} c_{s i}^{1-\gamma}
$$

The consumer in country $i$ consumes a final good, $y$,

$$
y_{i}=q_{i}^{\mu} s_{i}^{1-\mu},
$$

where $q_{i}$, a composite retail good, is given by

$$
q_{i}=\left[\int_{0}^{1} m_{q i}(x)^{1-\frac{1}{\eta}} d x\right]^{\frac{\eta}{\eta-1}} .
$$

The markets for the intermediate composite, labor and capital must clear. Furthermore, the total units of distribution services required to deliver base goods to the consumer cannot exceed the output of distribution services. Therefore

$$
\int_{0}^{1} \phi_{i}(x) \bar{m}_{q i}(x) d x \leq d_{i}
$$

The price at which the importing firm buys good $x, \bar{p}_{m i}(x)$, remains unchanged and is given by Eq. (3.1). However, now I am going to refer to this as the producer price of good $x$. The retail price of base good $x$ is the sum of the producer price of good $x$ and the value of distribution services used to deliver 1 unit of the good, and so

$$
p_{m i}(x)=\bar{p}_{m i}(x)+\phi_{i}(x) p_{d i}
$$

The price of distribution services, $p_{d i}$, is given by

$$
p_{d i}=C w_{i}^{\delta} p_{c i}^{1-\delta} k_{i}^{-\alpha \delta}
$$

where $C=\delta^{-\delta}(1-\delta)^{(\delta-1)} \alpha^{-\alpha \delta}(1-\alpha)^{\delta(\alpha-1)}(\alpha /(1-\alpha))^{\alpha \delta}$. Eq. (6.1) shows that the retail price of good $x$ is going to differ across countries for two reasons: (i) the producer price 
can be different across countries because of the presence of trade costs, and (ii) the costs of distribution can be different across countries because of differences in the price of distribution services and differences in the number of units of distribution services used. $\theta$ will now control the variation in producer price dispersion across goods. Like $\theta, \nu$ controls the variation in the degree of dispersion distribution costs (per unit of the good) across goods.

Since $\bar{p}_{m i}(x)$ is unchanged, it implies that the price of intermediate composite is also unchanged and is given by Eq. (3.5).

\subsection{Model Solution and Simulation of Prices}

The zero profit condition in the retail goods sector implies that $L_{i} V_{m i}=L_{i} \bar{V}_{m i}+L_{i} p_{d i} d_{i}$. $V_{m i}$ is the per capita retail value of all base goods, and $\bar{V}_{m i}$ is the per capita producer price value of all base goods. Define $\vartheta_{i}$ as the ratio of value of distribution services and retail value of base goods in country $i$, i.e. $\vartheta_{i}=L_{i} p_{d i} d_{i} / L_{i} V_{m i}$. With the inclusion of a distribution sector, the share of the base goods sector in the labor force is $l_{m i}=1-l_{d i}-l_{s i}=1-\mu \delta \vartheta_{i}-\gamma(1-\mu)$. Now, the balanced trade condition is given by:

$$
\sum_{j=1}^{N} L_{j} w_{j} l_{m j} D_{j i}=L_{i} w_{i} l_{m i}
$$

The solution methodology remains the same: I take the endowment of labor and capital from data, estimate trade costs from the gravity equation, Eq. (3.3), solve for $w_{i}$ and $p_{c i}$ using Eq. (6.3) and Eq. (3.6), and calibrate $\lambda_{i}$ using Eq. (3.8). $\vartheta_{i}$ is estimated from the data (see Appendix B for details).

I simulate the model by drawing idiosyncratic costs for goods $\left(z_{i}(x)\right)$ for each country from the country-specific distribution $\left(\exp \left(\lambda_{i}\right)\right)$, and then use Eq. (3.1) to compute the producer prices of the goods. Then, for every country $i$, the unit distribution services requirement for goods, $u_{i}(x)$, is drawn from the common density function $g=e^{-u}$. The retail price of each good is calculated using Eq. (6.1). The deviation from the LOOP, $Q_{m i}(x)$, is computed using Eq. (3.9), but for retail prices. Good-by-good price dispersion is given by $\operatorname{Var}\left(Q_{m i}(x) \mid x\right)^{1 / 2}$. The distribution margin for good $x$ is calculated as:

$$
d m_{i}(x)=1-\frac{\bar{p}_{m i}(x)}{p_{m i}(x)} .
$$

Again, number of goods is 1500 and the number of simulations is 100 . 


\subsection{Data on Distribution Margins}

Following Goldberg and Campa (Forthcoming), I compute distribution margins - distribution costs as a ratio of retail value - for 29 product categories in each country. The data come from input-output tables, specifically the use tables, which provide information on the value of the supply of goods in "basic price" and the value of the same goods in "purchaser price". The difference between basic price and purchaser price is that the latter includes distribution margins and value added taxes (or subsidies), whereas the former does not. The distribution margin for a good is calculated as:

$$
\text { Distribution Margin }=\frac{\text { Supply in Purchaser Prices }- \text { Supply in Basic Prices }}{\text { Supply in Purchaser Prices }}
$$

Care is taken to exclude net taxes from the purchaser price value of each good. ${ }^{18}$ For the EU countries, goods are classified according to the Classification of Products by Activities (CPA) classification of goods. Australia, New Zealand, the United States and Japan do not use the CPA classification of goods. Since the EU countries form the majority of countries in my sample, the commodity classifications of the non-EU countries were mapped into the CPA classification. Only those product categories were chosen for which the distribution margins were non-negative. The data show that distribution margins are zero or negative for almost all services across countries. This is consistent with the findings of Goldberg and Campa (Forthcoming). In addition, the CPA product category 'Uranium and thorium ores' was excluded because of missing data. For most countries in the sample, data are available for the year 1995. For Australia, data are available for 2001-02, for Norway they are available for 2001, for Ireland they are available for 1998 and for the United States they are available for 1997. Data are not available for Canada, Mexico and Switzerland.

For the countries for which I have data over multiple years, I find that distribution margins do not change significantly from one year to another for individual product categories. Consequently, the inconsistency between the years for which distribution costs data are available and the year to which the benchmark model is calibrated (1996) is a non-issue.

Table 7 provides three statistics on distribution margins by country across goods - the

\footnotetext{
${ }^{18}$ For Japan and the United States, data on net taxes are not available. Therefore, for these countries purchaser price value could not be adjusted for net taxes.
} 
average, the maximum and the minimum value. The second column shows that Japan has the highest average distribution margin, whereas Ireland has the lowest. ${ }^{19}$ The last two columns show that within each country, there is a large variation in distribution margins across goods.

Table 7: Distribution Margins by Countries

\begin{tabular}{lrrr}
\hline \hline Country & Average & Maximum & Minimum \\
\hline Australia & 0.2329 & 0.5698 & 0.0794 \\
Austria & 0.1833 & 0.4408 & 0.0000 \\
Belgium & 0.1540 & 0.3800 & 0.0569 \\
Denmark & 0.1952 & 0.3993 & 0.0000 \\
Finland & 0.1683 & 0.6302 & 0.0233 \\
France & 0.1567 & 0.3832 & 0.0107 \\
Germany & 0.2012 & 0.4658 & 0.0677 \\
Greece & 0.2063 & 0.4734 & 0.0001 \\
Ireland & 0.1022 & 0.2728 & 0.0000 \\
Italy & 0.2041 & 0.4768 & 0.0040 \\
Japan & 0.3361 & 0.9275 & 0.1015 \\
Netherlands & 0.1752 & 0.4382 & 0.0004 \\
New Zealand & 0.1338 & 0.2825 & 0.0000 \\
Norway & 0.2352 & 0.7141 & 0.0000 \\
Portugal & 0.1489 & 0.3974 & 0.0000 \\
Spain & 0.1644 & 0.4301 & 0.0003 \\
Sweden & 0.1612 & 0.4851 & 0.0000 \\
United Kingdom & 0.1810 & 0.4921 & 0.0010 \\
United States & 0.2753 & 0.7215 & 0.0537 \\
\hline \hline
\end{tabular}

Table 8 lists the average, the maximum and the minimum distribution margin across countries for each CPA product category. 'Wearing apparel; furs' has the highest average distribution margin across countries. On the other hand 'Other transport equipment' has the lowest average margin. Looking at the last two columns, it is clear that even for the same good there is significant variation in distribution margins across countries.

Table 8: Distribution Margins by Goods

\begin{tabular}{lrrr}
\hline \hline CPA Product & Average & Maximum & Minimum \\
\hline Products of agriculture, hunting and related services & 0.1662 & 0.3015 & 0.0141 \\
Products of forestry, logging and related services & 0.1449 & 0.4301 & 0.0000 \\
Fish and other fishing products; services incidental of fishing & 0.2424 & 0.4768 & 0.0000 \\
Coal and lignite; peat & 0.1530 & 0.6833 & 0.0000 \\
Crude petroleum and natural gas; services incidental to oil & 0.1022 & 0.8925 & 0.0000 \\
and gas extraction excluding surveying & & & \\
\hline
\end{tabular}

${ }^{19}$ These numbers are based on distribution margins for all expenditures. Burstein et al. (2003), using data only on final consumption expenditure, show that distribution margins are higher - average of 40 percent for U.S. and 60 percent for Argentina. However, such data are not available at the good level for most countries in my sample. 
Table 8: (continued)

\begin{tabular}{lrrr}
\hline \hline CPA Product & Average & Maximum & Minimum \\
\hline Metal ores & 0.1262 & 0.9275 & 0.0000 \\
Other mining and quarrying products & 0.2015 & 0.4109 & 0.0000 \\
Food products and beverages & 0.2187 & 0.3901 & 0.0954 \\
Tobacco products & 0.3650 & 0.7141 & 0.1102 \\
Textiles & 0.2250 & 0.4327 & 0.0978 \\
Wearing apparel; furs & 0.3979 & 0.6000 & 0.2112 \\
Leather and leather products & 0.3582 & 0.7215 & 0.1237 \\
Wood and products of wood and cork (except furniture); & 0.1452 & 0.3085 & 0.0306 \\
articles of straw and plaiting materials & & & 0.0472 \\
Pulp, paper and paper products & 0.1383 & 0.2282 & 0.0570 \\
Printed matter and recorded media & 0.1657 & 0.2752 & 0.0000 \\
Coke, refined petroleum products and nuclear fuels & 0.2118 & 0.4323 & 0.0348 \\
Chemicals, chemical products and man-made fibres & 0.1827 & 0.2767 & 0.0523 \\
Rubber and plastic products & 0.1468 & 0.2647 & 0.0574 \\
Other non-metallic mineral products & 0.1730 & 0.2906 \\
Basic metals & 0.1013 & 0.1633 & 0.0371 \\
Fabricated metal products, except machinery and equipment & 0.1400 & 0.2728 & 0.0718 \\
Machinery and equipment n.e.c. & 0.1499 & 0.2632 & 0.0410 \\
Office machinery and computers & 0.2073 & 0.3993 & 0.0448 \\
Electrical machinery and apparatus n.e.c. & 0.1537 & 0.3557 & 0.0581 \\
Radio, television and communication equipment and apparatus & 0.1513 & 0.2384 & 0.0729 \\
Medical, precision and optical instruments, watches and clocks & 0.2099 & 0.3975 & 0.0667 \\
Motor vehicles, trailers and semi-trailers & 0.1815 & 0.3376 & 0.0744 \\
Other transport equipment & 0.0819 & 0.2825 & 0.0213 \\
Furniture; other manufactured goods n.e.c. & 0.2904 & 0.4821 & 0.1300 \\
\hline \hline
\end{tabular}

It is clear from the data that distribution margins vary widely across goods and across countries. The cross-country and cross-product trends in distribution margins are the same as those reported by Goldberg and Campa (Forthcoming). The size of distribution margins is also similar. ${ }^{20}$ There are small differences because for some countries they use data from a different year, and in addition to the countries listed in Table 7, they include Estonia, Hungary and Poland.

\subsection{Calibration}

As in the model without distribution costs, agriculture, hunting, forestry and fishing, mining and quarying, and manufacturing are treated as the traded goods sector. Wholesale trade, retail trade and transport and storage form the distribution services sector. All other

\footnotetext{
${ }^{20}$ Goldberg and Campa (Forthcoming) compute average distribution margin as one minus the ratio of total supply of all goods in basic prices to total supply in purchaser's prices. This is different from averaging the distribution margins across product categories, as I do.
} 
sectors form the non-traded good sector. The calibrated values of $\beta, \alpha, \eta$ and $\theta$ remain unchanged. $\delta$ and $\gamma$ are calibrated as the share of value added in gross output of distribution services sector and the non-traded good sector, respectively. $\mu$ is the share of the composite retail good in value of output of the final good sector. $\mu$ is computed as one minus the share of the non-traded good sector (all services except retail trade, wholesale trade and transport and storage) in GDP. Details of the data and the methodology are provided in Appendix B. For the sample of countries $\delta$ is $0.58, \gamma$ is 0.62 and $\mu$ is 0.42 . Again, these are averages for the period 1995-1997.

Heterogeneity in distribution margins is used as a target to calibrate $\nu$. First, using the model-simulated distribution margins, the standard deviation of distribution margins across all goods in each country is computed. Then, an average of these country-specific standard deviations is computed. $\nu$ is chosen so that this model-generated average standard deviation is equal to its data counterpart (which is 11.5 percent). I find $\nu$ to be 0.75 . $\zeta_{i}$ is chosen so that the average of the simulated distribution margins of all goods in country $i$ equals the average of distribution margins of all goods in country $i$ observed in the data (as reported in Table 7). The average distribution margin for countries with missing data (Canada, Mexico and Switzerland) is replaced by the sample average in the data. Table 9 gives the calibrated $\zeta$ for each country.

Table 9: Country-Specific Distribution Parameter: $\zeta_{i}$

\begin{tabular}{lr|lr|lr|lr}
\hline \hline Country & $\zeta$ & Country & $\zeta$ & Country & $\zeta$ & Country & $\zeta$ \\
\hline Australia & 0.28 & Finland & 0.13 & Italy & 0.16 & Spain & 0.15 \\
Austria & 0.18 & France & 0.12 & Japan & 0.33 & New Zealand & 0.16 \\
Belgium & 0.09 & Germany & 0.14 & Mexico & 0.20 & Sweden & 0.11 \\
Canada & 0.18 & Greece & 0.20 & Netherlands & 0.12 & Switzerland & 0.15 \\
Denmark & 0.16 & Ireland & 0.06 & Norway & 0.13 & United Kingdom & 0.15 \\
& & & & Portugal & 0.17 & United States & 0.25 \\
\hline \hline
\end{tabular}

Table 15, in Appendix C, summarizes the parameterization of the Ricardian model with distribution sector.

\section{Results: Ricardian Model with Distribution}

Table 10 shows that the model accounts for 96 percent of the average price dispersion and 32 percent of the dispersion in price dispersion. Thus, incorporating differences in costs 
of distribution across countries in the EK model helps to account for the average price dispersion for a basket of goods almost perfectly and improves the model's performance in matching the variation. It is also evident that distribution costs play a more important role in matching the variation in good-by-good price dispersion than in matching the average good-by-good price dispersion in retail prices observed in the data. Figure 4 plots the empirical distribution of good-by-good price dispersion generated by the Ricardian model with distribution costs, as well as that generated by the model without distribution costs.

Table 10: Good-by-Good Price Dispersion: Model Versus Data

\begin{tabular}{lrrr}
\hline \hline & Model & Data & Model as ratio of Data \\
\hline Avg. & 0.2658 & 0.2778 & 0.9569 \\
Stdev & 0.0384 & 0.1216 & 0.3159 \\
\hline
\end{tabular}

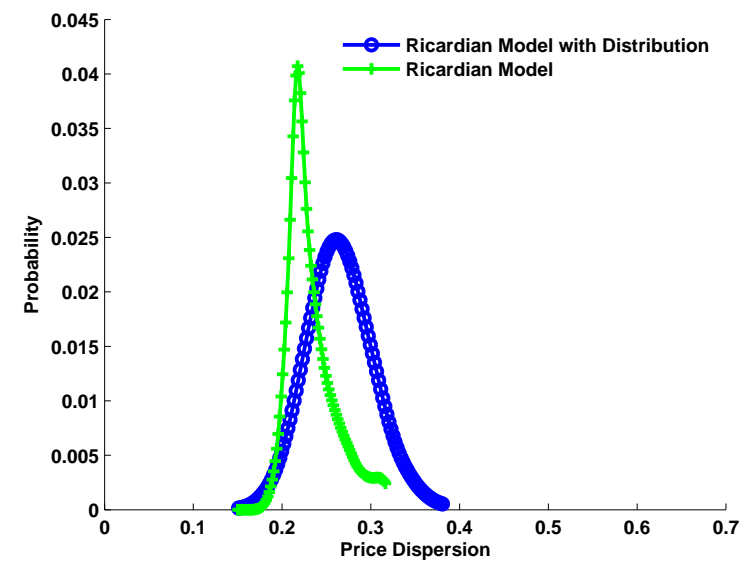

Figure 4: Distribution of $\operatorname{Var}\left(Q_{m i}(x) \mid x\right)^{1 / 2}$

How is good-by-good price dispersion related to the use of traded and non-traded inputs? The share of non-traded input in the retail price of a good is given by the distribution margin, whereas the share of traded input - producer price margin - is the ratio of producer price to the retail price of a good. The next figure shows the relationship between the dispersion in LOOP deviations of a good and the average distribution margin (and producer price margin), across countries, of a good. Figure 5(a) shows that goods with higher price dispersion have a higher average distribution margin. Since the producer price margin is one minus the distribution margin, the average producer price margin falls as good-by-good price dispersion rises. The good with the highest dispersion in LOOP deviations has an average 


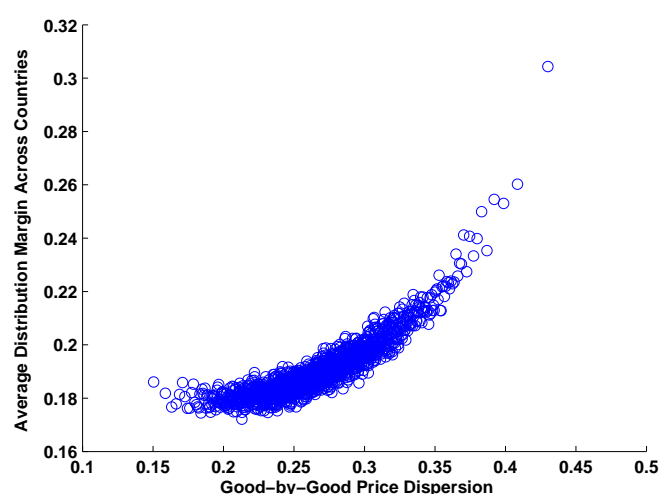

(a) Non-traded - Distribution Margin

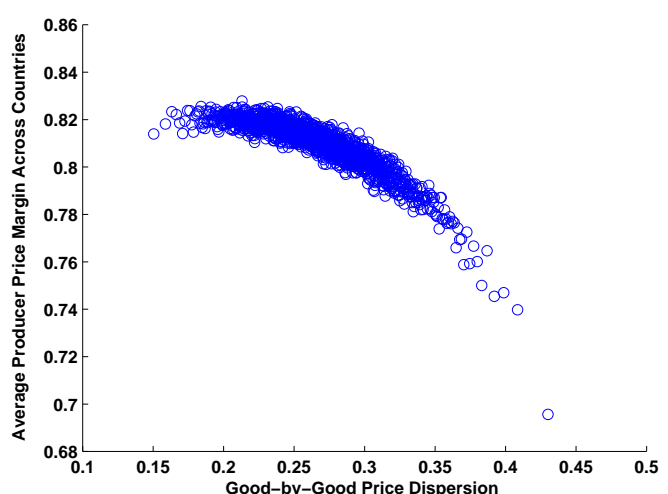

(b) Traded - Producer Price Margin

Figure 5: Good-by-Good Price Dispersion Versus Intensity of Traded and Non-traded Inputs distribution margin of 30 percent whereas the good with the lowest dispersion has an average distribution margin of 19 percent. Thus, retail goods that are intensive in non-traded inputs show higher price dispersion as compared to those that are intensive in traded-inputs.

\section{Sectoral Heterogeneity}

The analysis so far has shown that the multi-country Ricardian model with distribution costs is suitable for accounting for the average price dispersion for a basket of goods. However, it does a poor job of generating the differences in price dispersion across different types of goods. The inability of the model to match the variation in price dispersion results from insufficient heterogeneity in trade costs and distributions costs across goods. To capture greater heterogeneity in the two sources of LOOP deviations, I extend the baseline model of trade and retailing to a multi-sector framework. This allows us to exploit the differences in trade volumes and distribution costs across sectors and countries, observed in the data.

The model is based on the work of Giri et al. (2011). Now base goods that are traded between countries can belong to one of the $t=1, \ldots, T$ traded goods sectors. Each country produces a continuum of base goods $x^{t} \in[0,1]$ in each sector $t$. The output of good $x$ of sector $t$ in country $i$ is given by

$$
m_{i}^{t}\left(x^{t}\right)=z_{i}^{t}\left(x^{t}\right)^{-\theta}\left[k_{i}^{t}\left(x^{t}\right)^{\alpha} l_{i}^{t}\left(x^{t}\right)^{1-\alpha}\right]^{\beta^{t}}\left[\left(\sum_{h=1}^{T} c_{i}^{h}\left(x^{t}\right)^{\frac{\varphi-1}{\varphi}}\right)^{\frac{\varphi}{\varphi-1}}\right]^{1-\beta^{t}},
$$

where $k_{i}^{t}\left(x^{t}\right)$ and $l_{i}^{t}\left(x^{t}\right)$ are the amounts of capital and labor used to produce good $x$ of 
sector $t$ in country $i ; c_{i}^{h}\left(x^{t}\right)$ is the amount of intermediate composite of sector $h$ used to produce good $x$ of sector $t$ and $z_{i}^{t}\left(x^{t}\right)$ is the random cost draw for the good. $z_{i}^{t}\left(x^{t}\right)$ 's are drawn from an exponential distribution - $\exp \left(\lambda_{i}^{t}\right)$. Furthermore, $z_{i}^{t}\left(x^{t}\right)$ 's are assumed to be independent across goods, sectors and countries.

Now the bilateral iceberg costs are sector-specific. So, transporting 1 unit of a good of sector $t$ from country $j$ to $i$ incurs an iceberg cost of $\tau_{i j}^{t}>1$ for $i \neq j$, and $\tau_{i i}^{t}=1$ for all $i$. Then the producer price of good $x$ of sector $t$ in country $i$ is

$$
\bar{p}_{m i}^{t}\left(x^{t}\right)=\min _{j}\left\{B^{t} V_{j}^{t} z_{j}^{t}\left(x^{t}\right)^{\theta} \tau_{i j}^{t}\right\}
$$

where

$$
V_{i}^{t}=\left[r_{i}^{\alpha} w_{i}^{1-\alpha}\right]^{\beta^{t}}\left[\left(\sum_{h=1}^{T}\left(p_{c i}^{h}\right)^{1-\varphi}\right)^{\frac{1}{1-\varphi}}\right]^{1-\beta^{t}}
$$

and

$$
B^{t}=\left(\beta^{t}\right)^{-\beta^{t}}\left(1-\beta^{t}\right)^{-\left(1-\beta^{t}\right)}(\alpha)^{-\alpha \beta^{t}}(1-\alpha)^{-\beta^{t}(1-\alpha)}
$$

Analogous to the one sector model, the amount of base good $x$ of sector $t$ bought by the importing firm, $\bar{m}_{i}^{t}\left(x^{t}\right)$, is divided into two parts - $\bar{m}_{c i}^{t}\left(x^{t}\right)$ used to produce the intermediate composite of sector $t$ and $\bar{m}_{q i}^{t}\left(x^{t}\right)$ bought by the retailer:

$$
\bar{m}_{i}^{t}\left(x^{t}\right)=\bar{m}_{c i}^{t}\left(x^{t}\right)+\bar{m}_{q i}^{t}\left(x^{t}\right)
$$

Sector $t$ intermediate composite $c_{i}^{t}$ is defined as

$$
c_{i}^{t}=\left[\int_{0}^{\infty} \bar{m}_{c i}^{t}\left(x^{t}\right)^{\frac{\eta-1}{\eta}} f^{t}\left(z^{t}\right) d z^{t}\right]^{\frac{\eta}{\eta-1}},
$$

where $f^{t}\left(z^{t}\right)$ is the joint density function for sector $t$ cost draws:

$$
f^{t}\left(z^{t}\right)=\left(\prod_{i=1}^{N} \lambda_{i}^{t}\right) \exp \left(-\sum_{i=1}^{N} \lambda_{i}^{t} z_{i}^{t}\right) .
$$

To deliver one unit of good $x$ of sector $t$ to the consumer the retailer uses $\phi_{i}^{t}\left(x^{t}\right)$ units of distribution services,

$$
\phi_{i}^{t}\left(x^{t}\right)=\zeta_{i}^{t} u\left(x^{t}\right)^{\nu}
$$

where $\zeta_{i}^{t}$ reflects country $i$ 's efficiency in distribution of goods of sector $t$, and $u$ is a random draw from a common density function $g=\exp (1)$. The draws are assumed to be independent 
across goods and sectors. For a given base good $x, u$ and $z$ (random cost draw for base good $x)$ are also assumed to be independent. Output of retail good $x$ of sector $t$ is denoted by $m_{q i}^{t}\left(x^{t}\right)$.

Distribution services, $d_{i}$, are produced with labor, $l_{d i}$, capital, $k_{d i}$, and intermediate composites, $c_{i}^{d, t}$, using Cobb-Douglas technology which is given by ${ }^{21}$

$$
d_{i}=\left[k_{d i}^{\alpha} l_{d i}^{1-\alpha}\right]^{\delta}\left[\left(\sum_{t=1}^{T}\left(c_{i}^{d, t}\right)^{\frac{\varphi-1}{\varphi}}\right)^{\frac{\varphi}{\varphi-1}}\right]^{1-\delta} .
$$

Now, the retail price of good $x$ of sector $t$ in country $i$ is

$$
p_{m i}^{t}\left(x^{t}\right)=\bar{p}_{m i}^{t}\left(x^{t}\right)+\phi_{i}^{t}\left(x^{t}\right) p_{d i}
$$

where $p_{d i}$, the price of distribution services, is given by

$$
p_{d i}=C\left[r_{i}^{\alpha} w_{i}^{1-\alpha}\right]^{\delta}\left[\left(\sum_{h=1}^{T}\left(p_{c i}^{h}\right)^{1-\varphi}\right)^{\frac{1}{1-\varphi}}\right]^{1-\delta},
$$

and

$$
C=(\delta)^{-\delta}(1-\delta)^{-(1-\delta)}(\alpha)^{-\alpha \delta}(1-\alpha)^{-\delta(1-\alpha)}
$$

In addition to producing distribution services each country also produces a homogeneous non-traded good.

$$
s_{i}=\left[k_{s i}^{\alpha} l_{s i}^{1-\alpha}\right]^{\gamma}\left[\left(\sum_{t=1}^{T}\left(c_{i}^{s, t}\right)^{\frac{\varphi-1}{\varphi}}\right)^{\frac{\varphi}{\varphi-1}}\right]^{1-\gamma} .
$$

The consumer in country $i$ consumes a final good, $y$,

$$
y_{i}=\left[\prod_{t=1}^{T}\left(q_{i}^{t}\right)^{\omega^{t}}\right]^{\mu} s_{i}^{1-\mu}
$$

where $q_{i}^{t}$, sector $t$ composite retail good, is given by

$$
q_{i}^{t}=\left[\int_{0}^{1} m_{q i}^{t}\left(x^{t}\right)^{1-\frac{1}{\eta}} d x\right]^{\frac{\eta}{\eta-1}} .
$$

\footnotetext{
${ }^{21}$ The total units of distribution services required to deliver base goods to the consumer cannot exceed the output of distribution services - $\sum_{t=1}^{T} \int_{0}^{1} \phi_{i}^{t}\left(x^{t}\right) \bar{m}_{q i}^{t}\left(x^{t}\right) d x^{t} \leq d_{i}$.
} 
The methodology to solve and simulate the model remains the same as that adopted in solving the one sector model. The key equations and the main steps are described below: Step 1 - Estimate trade costs, $\tau_{i j}^{t}$, and country dummies, $S_{i}^{t}$, using ${ }^{22}$

$$
\begin{gathered}
D_{i j}^{t}=\left(A B^{t}\right)^{-\frac{1}{\theta}}\left(\frac{V_{j}^{t} \tau_{i j}^{t}}{p_{c i}^{t}}\right)^{\frac{-1}{\theta}} \lambda_{j}^{t}, \\
\ln \left(\frac{D_{i j}^{t}}{D_{i i}^{t}}\right)=S_{j}^{t}-S_{i}^{t}-\frac{1}{\theta} \ln \left(\tau_{i j}^{t}\right), \\
\ln \tau_{i j}^{t}=\underbrace{d i s t_{I}}_{\text {distance }}+\underbrace{\operatorname{brdr} r}_{\text {border }}+\underbrace{\text { lang }}_{\text {language }}+\underbrace{t b l k_{M}}_{\text {trade block }}+\underbrace{\text { dest } t_{i}^{t}}_{\text {destination effect }}+\varepsilon_{i j}^{t} .
\end{gathered}
$$

$S_{i}^{t}=\ln \left(\Omega_{i}^{t}\right)$, and $\Omega_{i}^{t}=\left(V_{i}^{t}\right)^{-\frac{1}{\theta}} \lambda_{i}^{t}$.

Step 2 - Compute price of sector $t$ intermediate composite using:

$$
p_{c i}^{t}=A B^{t}\left(\sum_{j=1}^{N} e^{S_{j}^{t}} \tau_{i j}^{t}-\frac{1}{\theta}\right)^{-\theta} .
$$

Also compute

$$
\bar{p}_{c i}=\left(\sum_{h=1}^{T}\left(p_{c i}^{h}\right)^{1-\varphi}\right)^{\frac{1}{1-\varphi}} .
$$

Step 3 - Taking $L_{i}$ and $D_{i j}^{t}$ from the data, solve for $l_{i}^{t}$ and $X_{i}^{t}$ as functions of $w_{i}$, and use the balanced trade condition to solve for $w_{i}{ }^{23}$

$$
\begin{gathered}
L_{i} w_{i} l_{i}^{t}=\beta^{t} \sum_{j=1}^{N} L_{j} w_{j}\left[\left(\frac{p_{c j}^{t}}{\bar{p}_{c j}}\right)^{1-\varphi}\left(\sum_{h=1}^{T} \frac{\left(1-\beta^{h}\right)}{\beta^{h}} l_{j}^{h}+\frac{(1-\delta)}{\delta} l_{d j}+\frac{(1-\gamma)}{\gamma} l_{s j}\right)\right] D_{j i}^{t}, \\
X_{i}^{t}=\frac{w_{i}}{(1-\alpha)}\left[\left(\frac{p_{c i}^{t}}{\bar{p}_{c i}}\right)^{1-\varphi}\left(\sum_{h=1}^{T} \frac{\left(1-\beta^{h}\right)}{\beta^{h}} l_{i}^{h}+\frac{(1-\delta)}{\delta} l_{d i}+\frac{(1-\gamma)}{\gamma} l_{s i}\right)\right],
\end{gathered}
$$

\footnotetext{
${ }^{22}$ Because of the presence of some zero-trade observations in the sectoral trade data, I employ poisson pseudo maximum likelihood (PPML) estimation as advocated in Silva and Tenreyro (2006).

${ }^{23}$ Start with the market clearing condition for intermediate composite of sector $t-X_{i}^{t}=p_{c i}^{t} c_{i}^{t}=$ $p_{c i}^{t} \sum_{h=1}^{T} c_{i}^{h, t}+p_{c i}^{t} c_{i}^{d, t}+p_{c i}^{t} c_{i}^{s, t}$. In the distribution sector $-p_{c i}^{t} c_{i}^{d, t}=\frac{(1-\delta)}{\delta(1-\alpha)}\left(\frac{p_{c i}^{t}}{\bar{p}_{c i}}\right)^{1-\varphi} w_{i} l_{d i}$. Similarly $p_{c i}^{t} c_{i}^{s, t}=$ $\frac{(1-\gamma)}{\gamma(1-\alpha)}\left(\frac{p_{\bar{p}}^{t}}{\bar{p}_{c i}}\right)^{1-\varphi} w_{i} l_{s i}$. Because of Cobb-Douglas production technology and CES aggregator of intermediates the expenditure by sector $h$ on intermediate composite of sector $t$ is $-p_{c i}^{t} c_{i}^{h, t}=\frac{\left(1-\beta^{h}\right)}{\beta^{h}(1-\alpha)}\left(\frac{p_{c i}^{t}}{\bar{p}_{c i}}\right)^{1-\varphi} w_{i} l_{i}^{h}$. Lastly, the expenditure on labor used in production of sector $t$ goods is $-L_{i} w_{i} l_{i}^{t}=\beta^{t}(1-\alpha) \sum_{j=1}^{N} L_{j} X_{j}^{t} D_{j i}^{t}$.
} 
where $l_{s i}=\gamma(1-\mu)$ and $l_{d i}=1-l_{s i}-\sum_{t=1}^{T} l_{i}^{t}$.

Step 4 - The productivity parameter for sector $t$ in country $i, \lambda_{i}^{t}$, is obtained using the relationship

$$
\left(V_{i}^{t}\right)^{-\frac{1}{\theta}} \lambda_{i}^{t}=\Omega_{i}^{t}=e^{S_{i}^{t}}
$$

where $V_{i}^{t}$ is the factor cost, given by (8.2). Given the data on capital-labor ratio, $k_{i}$, interest rate, $r_{i}$, is obtained from the relationship

$$
r_{i} k_{i}=\frac{\alpha}{1-\alpha} w_{i}
$$

Step 5 - I simulate the model by drawing idiosyncratic costs for goods of each sector, $z_{i}^{t}\left(x^{t}\right)$, from the country-sector specific distribution $\exp \left(\lambda_{i}^{t}\right)$, and then use Eq. (8.1) to compute the producer prices of the goods. Then, for every good of each sector in each country the unit distribution services requirement, $u\left(x^{t}\right)$, is drawn from the common density function $g=e^{-u}$. The retail price of each good is calculated using Eq. (8.3), which is then used to compute the LOOP deviations and good-by-good price dispersion.

\subsection{Data and Calibration}

Data on gross output, value added and bilateral trade by sectors come from Giri et al. (2011) who use data from the Trade, Production and Protection database of the World Bank for $1990 .^{24}$ The database covers the manufacturing sector by disaggregating it into 28 sub-sectors corresponding to the 3-digit level International Standard Industrial Classification (ISIC), Revision 2. Because of problems of missing observations for bilateral trade volumes, I aggregate the 28 manufacturing sectors into 9. In addition, I collect data from OECD STAN Industrial database on agriculture, hunting, forestry and fishing and mining and quarying to be consistent with the definition of traded goods sector in the one-sector model. This gives 11 traded good sectors. The description of the 11 sectors is provided in Table 14 in Appendix B. Construction of trade shares, $D_{i j}^{t}$, is unchanged with the only modification that now these are computed for each sector. Austria and Switzerland were dropped from

\footnotetext{
${ }^{24} 1990$ aggregate trade shares are not very different from the 1996 trade shares. Thus, the results of the one-sector model(s) with 1990 trade shares would be very similar to those with 1996 trade shares discussed earlier.
} 
the original set of 22 countries because of a large number of missing observations on trade volumes and output.

$\beta^{t}$ is computed as the average of the share of value added in gross output of a sector across countries. $\omega^{t}$ is computed as the average share of a sector in the total value added across all traded goods sectors, across countries. The elasticity of substitution between intermediate goods of different sectors, $\varphi$, is set at 0.5 . Change in the value of $\varphi$ does not effect price dispersion across goods since it affects the factor cost in all countries in a symmetric manner. In general, this elasticity should be less than the elasticity between goods of a sector, $\eta$, which is unchanged at 2 . All other common parameters between the one-sector and multi-sector model are unchanged, including $\theta$ and $\nu$. $\zeta_{i}^{t}$ is estimated by minimizing the sum of squared errors between data and the model for country-sector pair distribution margins:

$$
\min _{\zeta_{i}^{t}} \sum_{i=1}^{N} \sum_{t=1}^{T}\left(\widehat{d m}_{i}^{t}-d m_{i}^{t}\right)^{2}
$$

where $\widehat{d m}_{i}^{t}$ is distribution margin for sector $t$ in country $i$ in data, and $d m_{i}^{t}$ is the corresponding moment generated by the model. ${ }^{25}$ To construct distribution margins for the 11 sectors in each country, the 29 CPA product categories (shown in Table 8) were mapped into the 11 sectors. Each sector's distribution margin was computed as the weighted average of distribution margins of the mapped product categories. The weights were chosen to be the ratio of value (in purchaser prices net of taxes) of a product category to the sum of the values of all product categories in a sector. Missing values of distribution margin for Canada and Mexico were replaced by cross-country averages for the sectors.

\subsection{Results}

The results of the sectoral model are presented in Table 11. The model can account for 70 percent of the variation in price dispersion, though it overpredicts the average by 15 percent. The one-sector model could only account for 32 percent of the variation. Thus,

\footnotetext{
${ }^{25}$ Estimation of $\zeta_{i}^{t}$ is very time-intensive. Therefore, I increased the number of goods, per-sector, to 10000 and reduced the number of simulations to 1 . Due to the law of large numbers, the results do not change when the number of goods, per-sector, are reduced to 1000 and the number of simulations are increased to 10 .
} 
there is a big improvement in the model's ability to match the variation in price dispersion. Notably, it is the sectoral heterogeneity in distribution costs that drives this improvement. This becomes clear when these results are compared with the results of the multi-sector model without distribution costs (see Appendix D for details of the model) shown in the same table. The multi-sector model without distribution costs can account for 95 percent of the average price dispersion but only 26 percent of the variation in price dispersion. ${ }^{26}$

The distribution of good-by-good price dispersion, for goods of all sectors and for goods of each sector separately, for the two models is shown in Figure 7(a), 7(b) and Figure 6(a), $6(b)$.

Table 11: Good-by-Good Price Dispersion: Sectoral Model Versus Data

\begin{tabular}{lccc}
\hline \hline & Model & Data & Model as ratio of Data \\
\hline \multicolumn{4}{c}{ Model with distribution sector } \\
\hline Avg. & 0.3205 & 0.2778 & 1.1538 \\
Stdev & 0.08511 & 0.1216 & 0.7001 \\
\hline \multicolumn{4}{c}{ Model without distribution sector } \\
\hline Avg. & 0.2628 & 0.2778 & 0.9461 \\
Stdev & 0.0322 & 0.1216 & 0.2653 \\
\hline \hline
\end{tabular}

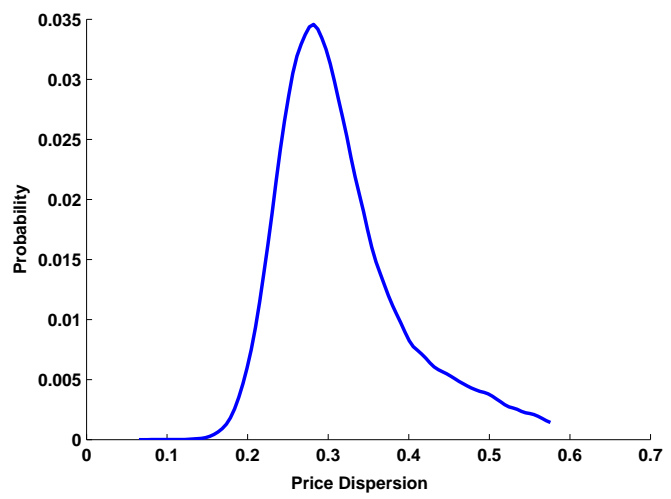

(a) All Sectors

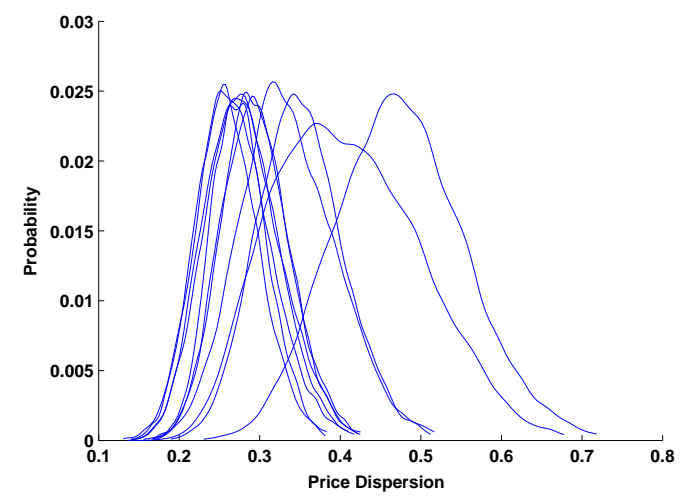

(b) For Each Sector

Figure 6: Good-by-Good Price Dispersion - Sectoral Model with Distribution Sector

So, sectoral heterogeneity in tradability of goods alone can account for the average price dispersion but does a poor job of generating the variation in price dispersion across

\footnotetext{
${ }^{26}$ Counter-factual of symmetric trade costs reduces the average price dispersion slightly (model accounts for 89 percent) and increases the variation by a relatively smaller amount (model accounts for 29 percent).
} 


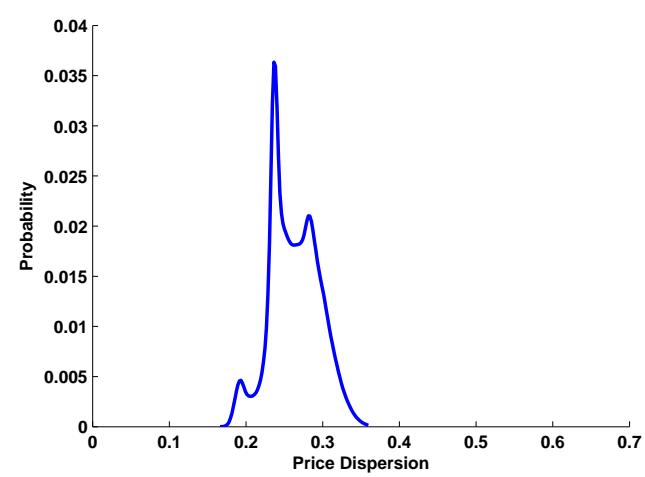

(a) All Sectors

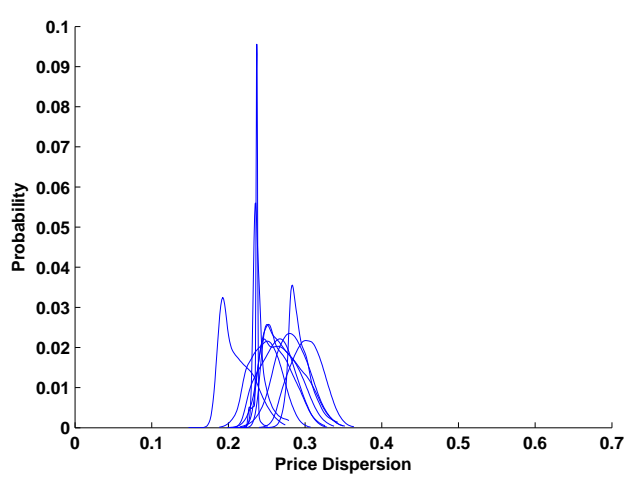

(b) For Each Sector

Figure 7: Good-by-Good Price Dispersion - Sectoral Model without Distribution Sector

goods. ${ }^{27}$ Incorporating sectoral heterogeneity in distribution costs improves the performance significantly with respect to matching the variation in price dispersion - it more than doubles the explanatory power.

In order to determine the relative importance of sectoral heterogeneity in tradability and distribution costs in driving the two moments of price dispersion I compute the correlation, across sectors, between the two moments of good-by-good price dispersion and the data used to estimate/calibrate trade costs and distribution costs - data on imports (as a share of total expenditure) and distribution margins. I focus on two moments in the data (i) average (Avg) imports and average distribution margins across countries for each sector, (ii) dispersion (StDev) in imports and dispersion in distribution margins across countries for each sector. In addition to using imports, I also use estimated trade costs as an alternate measure of tradability for goods of different sectors (average trade cost across country pairs and dispersion in trade costs across country pairs for each sector). Clearly, imports are a more comprehensive measure of tradability since they encompass not only trade costs but also marginal costs of production and the substitutability between goods. Table 12 shows the correlations.

For the model without distribution costs, both average trade costs and average imports are significantly correlated with the average price dispersion, as well as the variation in price dispersion. As compared to average trade costs, average imports show higher correlation

\footnotetext{
${ }^{27}$ Solving and simulating the model using the trade cost specification of Waugh (2009) yields similar results - model accounts for 95 percent of the average and 24 percent of the variation.
} 
with average price dispersion but a lower correlation with dispersion in price dispersion. Dispersion in trade costs and imports is significantly correlated with dispersion in goodby-good price dispersion, with dispersion in trade costs exhibiting higher correlation. In addition dispersion in imports is also highly correlated with average price dispersion, while dispersion in trade costs is not. This is because imports capture the effect of factors other than trade costs on tradability of goods - marginal costs of production and substitutability of goods.

Table 12: Correlation between Good-by-Good Price Dispersion and Sources of LOOP Deviations

\begin{tabular}{|c|c|c|c|c|c|c|}
\hline \multirow{2}{*}{$\begin{array}{l}\text { Good-by-good } \\
\text { price dispersion }\end{array}$} & \multicolumn{2}{|c|}{ Trade Costs } & \multicolumn{2}{|c|}{ Imports } & \multicolumn{2}{|c|}{ Distribution Margins } \\
\hline & Avg & StDev & Avg & StDev & Avg & StDev \\
\hline \multicolumn{7}{|c|}{ Model without distribution sector } \\
\hline Avg & 0.49 & 0.16 & -0.68 & -0.57 & & \\
\hline StDev & 0.68 & 0.64 & -0.56 & -0.48 & & \\
\hline \multicolumn{7}{|c|}{ Model with distribution sector } \\
\hline Avg & 0.05 & 0.02 & -0.10 & 0.12 & 0.62 & 0.87 \\
\hline StDev & -0.09 & -0.06 & 0.15 & 0.40 & 0.37 & 0.98 \\
\hline
\end{tabular}

These results change dramatically once distribution costs are taken into account. Both average trade costs and average imports are no longer significantly correlated with the moments of good-by-good price dispersion, though dispersion in imports still shows nonnegligible correlation with the variation in price dispersion. On the other hand, moments of distribution margins, both average and dispersion, are highly correlated with the moments of price dispersion. Average distribution margin shows high correlation with average price dispersion, and dispersion in distribution margins shows even higher correlation with both moments of price dispersion. These findings are presented graphically in Appendix D, with a simple linear regression line to infer the explanatory power of the sources of LOOP deviations. From Figure 8, it is clear that the dispersion in distribution margins is the most important factor explaining the moments of price dispersion.

\section{Conclusion}

This paper connects trade flows to deviations from LOOP in a structural model of trade and retailing. It accounts for the observed cross-country dispersion in prices of goods by focusing on two sources of goods market segmentation - (i) international trade costs, and 
(ii) local non-traded costs of distribution. I find that international trade costs and local distribution costs can account for the average price dispersion for a basket of goods fully and generate 70 percent of the differences in price dispersion across goods within the basket. While tradability of goods is important in explaining the average market segmentation for the entire basket of goods, distribution costs are important in explaining why, within the basket, some goods show more price dispersion than others.

The analysis also reveals that, in the one-sector EK model without distribution costs, the elasticity of substitution is crucial to match the data on price dispersion. Choosing the elasticity of substitution to match the two moments of good-by-good price dispersion implies values smaller than the preferred estimate of EK. The smaller estimates of elasticity imply higher welfare gains from trade as compared to those with the preferred estimate of EK. The smaller estimates also find support in some recent work in the literature.

However, in EK as well as in Simonovska and Waugh (2010), the method used to estimate the elasticity of substitution from international variation in retail prices crucially relies on the assumption that the production function of the retail good is Cobb-Douglas in local non-traded input and tradable input; only then the producer price can be separated from the local cost, and retail prices can be used in estimation. The model used in this paper deviates from this framework by introducing a Leontief production function to produce retail goods. If this was the case in the data, there would be another source of bias in EK estimation, and the 'true value' could be closer to the preferred EK estimate. ${ }^{28}$ In fact, the multi-sector model with distribution costs, using the benchmark value of the elasticity of substitution which is close to the preferred EK estimate, does very well in accounting for both moments of good-by-good price dispersion.

Therefore, micro data on prices certainly raise the question of what is the right estimate of the elasticity of substitution. Future research should focus on bringing together micro data on prices and trade volumes in a structural model for more accurate estimation of this elasticity, both at the aggregate level and at a more disaggregated level.

\footnotetext{
${ }^{28} \mathrm{I}$ thank the referee for pointing this out.
} 


\section{References}

Alvarez, Fernando and Robert E. Lucas, "General Equilibrium Analysis of the EatonKortum Model of International Trade," Journal of Monetary Economics, September 2007, 54, issue 6, 1726-1768.

Anderson, James E. and Eric Van Wincoop, "Trade Costs," Journal of Economic Literature, 2004, 42, 691-751.

Atkeson, Andrew and Ariel Burstein, "Pricing-to-Market, Trade Costs, and International Relative Prices," American Economic Review, December 2008, 98 (5), 19982031.

Bernard, Andrew B., Jonathan Eaton, Bradford J. Jensen, and Samuel Kortum, "Plants and Productivity in International Trade," American Economic Review, 2003, 93 (4), 1268-1290.

Betts, Caroline M. and Timothy J. Kehoe, "Tradability of Goods and Real Exchange Rate Fluctuations," FRB Minneapolis Research Department Staff Report, 2001.

Burstein, Ariel and Jonathan Vogel, "Globalization, Technology, and the Skill Premium," Discussion Paper, 2009.

Burstein, Ariel T., Joao C. Neves, and Sergio Rebelo, "Distribution Costs and Real Exchange Rate Dynamics during Exchange-Rate-Based Stabilizations," Journal of Monetary Economics, 2003, 50, 1189-1214.

Campa, J. M. and H.C. Wolf, "Is Real Exchange Rate Mean Reversion Caused by Arbitrage?," NBER Working Paper 6162, 1997.

Caselli, Francesco, "Accounting for Cross-Country Income Differences," Handbook of Economic Growth, 2005. ed. by P. Aghion, and S. Durlauf.

Corsetti, Giancarlo and Luca Dedola, "A Macroeconomic Model of International Price Discrimination," Journal of International Economics, 2005, 67, 129-155.

Crucini, Mario J. and Hakan Yilmazkuday, "A Model of International Cities: Implications for Real Exchange Rates," National Bureau of Economic Research, Inc., NBER Working Papers: No. 14834, April 2009.

- and Mototsugu Shintani, "Persistence in Law-of-One Price Deviations: Evidence from Micro-data," Journal of Monetary Economics, April 2008, 55 (3), 629-644. 
_, Chris I. Telmer, and Marios Zachariadis, "Understanding European Real Exchange Rates," American Economic Review, June 2005, 95 (3), 724-738.

Donaldson, Dave, "Railroads of the Raj: Estimating the Impact of Transportation Infrastructure," Working Paper, 2009.

Dornbusch, Rudiger, Stanley Fischer, and Paul A. Samuelson, "Comparative Advantage, Trade and Payments in a Riacrdian Model with Continuum of Goods," American Economic Review, 1977, 67, 823-839.

Eaton, Jonathan and Samuel Kortum, "Technology, Geography, and Trade," Econometrica, 2002, 70 (5), 1741-1779.

_, - , and Francis Kramarz, "An Anatomy of International Trade: Evidence from French Firms," NBER Working Paper 14610, 2008.

Engel, Charles and John H. Rogers, "European Product Market Integration after the Euro," Economic Policy, 2004, 19 (39), 347-384.

_, _, and Shing-Yi Wang, "Revisiting the Border: An Assessment of the Law of One Price Using Very Disaggregated Consumer Price Data," Exchange Rates, Capital Flows and Policy. Editors Rebecca Driver, Peter Sinclair and Christoph Thoenissen. London: Routledge, 2005, pp. 87-203.

Erceg, Christopher J. and Andrew T. Levin, "Structures and the Dynamic Behavior of the Real Exchange Rate.," Mimeo, Board of Governors of the Federal Reserve System., 1996.

Feenstra, Robert C., Robert E. Lipsey, Haiyan Deng, Alyson C. Ma, and Hengyong Mo, "World Trade Flows: 1962-2000," National Bureau of Economic Research, Inc., NBER Working Papers: No. 11040, January 2005.

Ghironi, Fabio and Marc J. Melitz, "International Trade and Macroeconomic Dynamics with Heterogeneous Firms," Quarterly Journal of Economics, 2005, 120 (3), 865-915.

Giri, Rahul, Kei-Mu Yi, and Hakan Yilmazkuday, "Gains from Trade: Does Sectoral Heterogeneity Matter?," Working Paper, 2011.

Goldberg, Linda and Jose Manuel Campa, "Distribution Margins, Imported Inputs, and the Sensitivity of the CPI to Exchange Rates," Review of Economics and Statistics, Forthcoming. 
Gollin, Douglas, "Getting Income Shares Right," Journal of Political Economy, 2002, 110, $458-474$.

Gorodnichenko, Yuriy and Linda Tesar, "Border Effect or Country Effect? Seattle May Not Be So Far from Vancouver After All," American Economic Journal: Macroeconomics, January 2009, 1 (1), 219-241.

Heston, Alan, Robert Summers, and Bettina Aten, "Penn World Table Version 6.1," Centre for International Comparisons at the University of Pennsylvania, 2002.

Knetter, Michael M., "International Comparisons of Price-to-Market Behavior," American Economic Review, June 1993, 83 (3), 473-486.

Krugman, Paul R., "Increasing Returns and Economic Geography," Journal of Political Economy, June 1991, 99 (3), 483-99.

McCallum, John, "National Borders Matter: Canada-U.S. Regional Trade Patterns," American Economic Review, June 1995, 85 (3), 615-23.

Nadarajah, Saralees, "A Review of Results on Sums of Random Variables," Acta Applicandae Mathematicae, March 2008, 103 (2), 131-140.

Rogers, John H., "Price Level Convergence, Relative Prices, and Inflation in Europe," Board of Governors of the Federal Reserve System (U.S.), International Finance Discussion Papers: No. 699, 2001.

Silva, Santos J. M. C. and Silvana Tenreyro, "The Log of Gravity," The Review of Economics and Statistics, November 2006, 88 (4), 641-658.

Simonovska, Ina and Michael E. Waugh, "The Elasticity of Trade: Estimates and Evidence," Working Paper, 2010.

Waugh, Michael E., "International Trade and Income Differences," Staff Report 435, Federal Reserve Bank of Minneapolis, September 2009.

\section{Appendix A}

The raw data on retail prices has substantial number of missing observations, which tend to increase over time because of inclusion of lower income countries that tend to consume fewer items of the survey's set of goods. Furthermore, Belgium has the least number of missing observations in every year, and Ireland has the most, except in 1990 in which 
case United Kingdom has the most missing observations. From the raw data, the authors eliminate any good that has insufficient number of cross-country observations, which they define as four in 1975, five in 1980, and six in 1985 and 1990. The increments are due to addition of new countries over time. Furthermore, in order to control for measurement error, goods for which the common currency price differs from the good-specific median by a factor of five or more are also eliminated. A substantial fraction of goods are labeled as "branded goods", which enhances the comparability of goods. The table below, reproduced from Crucini et al. (2005), gives the details of the raw data and the data after eliminating goods with insufficient data points and outliers.

Table 13: Scope of the Price Surveys

\begin{tabular}{lrrrr}
\hline \hline & 1975 & 1980 & 1985 & 1990 \\
\hline \multicolumn{4}{c}{ Panel A: Raw Survey } & Data \\
\hline Number of countries & 9 & 12 & 13 & 13 \\
Number of goods & 658 & 1090 & 1805 & 1896 \\
Proportion missing & $13 \%$ & $36 \%$ & $38 \%$ & $44 \%$ \\
Least missing & $9 \%$ & $23 \%$ & $25 \%$ & $32 \%$ \\
Most missing & $27 \%$ & $47 \%$ & $53 \%$ & $55 \%$ \\
Proportion of branded goods & $31 \%$ & $42 \%$ & $48 \%$ & $54 \%$ \\
\hline \multicolumn{4}{c}{ Panel B: After Eliminating goods } & with insufficient \\
\multicolumn{4}{c}{ data and outliers } \\
\hline Number of countries & 9 & 12 & 13 & 13 \\
Number of goods & 594 & 686 & 1164 & 1101 \\
Proportion missing & $10 \%$ & $17 \%$ & $19 \%$ & $23 \%$ \\
Least missing & $4 \%$ & $3 \%$ & $7 \%$ & $9 \%$ \\
Most missing & $22 \%$ & $28 \%$ & $37 \%$ & $34 \%$ \\
Proportion of branded goods & $31 \%$ & $28 \%$ & $33 \%$ & $38 \%$ \\
\hline \hline
\end{tabular}

\section{Appendix B}

\subsection{Data on Gross Output and Value Added}

The data used to compute the share of value added in gross output of the three sectors come from the OECD STAN Structural Analysis database (STAN Industry, ISIC Rev. 2 Vol 1998 release 01). Ratio of value added and gross output is calculated for each country in each sector (traded goods sector, distribution services and non-traded good sector) for three years - 1995, 1996 and 1997, and then averaged over these years to remove any idiosyncrasies associated with the year 1996. The ratios are then averaged across countries for each sector. Australia and Ireland are not included in this exercise because of missing data on gross 
output. The share of traded goods sector in GDP is calculated as the value added in traded good sector as a ratio of total value added in a country, and then averaged across countries. The share of non-traded good sector in GDP is computed in the same manner. Again, both ratios are averages for the period 1995-1997.

\subsection{Bilateral Trade Data and Expenditure Shares}

Data on bilateral trade volumes for the 22 OECD countries are obtained from the NBER-United Nations Trade Data, 1962-2000. Feenstra et al. (2005) provide the documentation for the data. The data are organized by the 4 digit Standard International Trade Classification, revision 2. Summing the exports of a country across all trading partners gives the country's total exports. Using the OECD STAN database, gross output of the traded goods sector for the year 1996 is obtained by adding gross output of the sub sectors. Gross output is expressed in nominal local currency units. Nominal yearly exchange rates with respect to the U.S. dollar for the year 1996 are used to convert local currency units into U.S. dollars. Data on nominal exchange rates come from OECD Economic Outlook, June, 2003, Annex Table 37. Subtracting total exports of a country from its gross output gives each country's home purchases. Adding home purchases and total imports of a country gives the country's total expenditure on traded goods. Normalizing home purchases and imports of an importing country from its trading partners by the importer's total expenditure on traded goods creates expenditure shares that are used in the model.

The data on distance, border and language used in the estimation of trade costs comes from Centre D'Etudes Prospectives Et D'Informations Internationales (http://www.cpeii.fr).

\subsection{Labor Force and Capital-Labor Ratio}

Capital-labor ratio data and data on labor force for 1996 come from Caselli (2005), and are based on Heston et al. (2002). Since data for Germany are missing, capital-labor ratio is computed as an average of capital-labor ratios of other countries. Missing data on labor force were replaced by data from World Development Indicators (WDI). 


\subsection{Basic Price Value of Traded Goods as a ratio of Purchaser Price Value of Traded Goods}

$\vartheta_{i}$ is computed from the data as 1 minus the ratio of basic price value of all traded goods and purchaser price value of all traded goods. These data are taken from the use tables of the countries. The basic price value of all traded goods is calculated as the sum of the supply of the 29 categories of goods valued in basic prices. The purchaser price value of all traded goods is calculated analogously. Since data for Canada, Mexico and Switzerland are not available, $\vartheta$ for these countries is assumed to be the average of $\vartheta_{\mathrm{s}}$ of the remaining 19 countries.

\subsection{List of Sectors for Sectoral Framework}

Table 14: List of Sectors

\begin{tabular}{cl}
\hline \hline Code & Description \\
\hline 100 & Agriculture, huntings, forestry, logging and fishing \\
200 & Mining and quarying \\
310 & Food products, beverages and tobacco \\
320 & Textiles, textile products, leather and footwear \\
330 & Wood and products of wood and cork \\
340 & Pulp, paper, paper products, printing and publishing \\
350 & Chemical, rubber, plastics and fuel products \\
360 & Other non-metallic mineral products \\
370 & Basic metals and fabricated metal products \\
380 & Machinery and equipment \\
390 & Transport equipment \\
\hline \hline
\end{tabular}

\section{Appendix C}

Table 15: Parameters

\begin{tabular}{|c|c|c|c|}
\hline Parameter & Description & Value & Source \\
\hline \multicolumn{4}{|c|}{ Panel A: Ricardian Model } \\
\hline$\theta$ & controls heterogeneity in productivities & 0.15 & Alvarez and Lucas (2007) \\
\hline$\eta$ & elasticity of substitution & 2 & Alvarez and Lucas (2007) \\
\hline$\beta$ & share of value added in gross output of traded goods & 0.36 & OECD STAN (Avg. 1995-1997) \\
\hline $1-\rho$ & share of traded good sector in GDP & 0.25 & OECD STAN (Avg. 1995-1997) \\
\hline$\alpha$ & share of capital in GDP & 0.33 & Gollin (2002) \\
\hline$\tau_{i j}$ & bilateral trade cost & & estimated from gravity equation \\
\hline$\lambda_{i}$ & absolute advantage in traded goods & & match share of country in its own ex- \\
\hline & & & penditure on traded goods \\
\hline \multicolumn{4}{|c|}{ Panel B: Ricardian Model with Distribution Costs } \\
\hline$\theta$ & Same as in the Ricardian Model & & \\
\hline$\eta$ & Same as in the Ricardian Model & & \\
\hline$\beta$ & Same as in the Ricardian Model & & \\
\hline$\alpha$ & Same as in the Ricardian Model & & \\
\hline
\end{tabular}


Table 15: (continued)

\begin{tabular}{llll}
\hline \hline Parameter & Description & Value & Source \\
\hline$\tau_{i j}$ & Same as in the Ricardian Model & & \\
$\lambda_{i}$ & Same as in the Ricardian Model & 0.58 & OECD STAN (Avg. 1995-1997) \\
$\delta$ & share of value added in gross output of distribution service & 0.62 & OECD STAN (Avg. 1995-1997) \\
$\gamma$ & share of value added in gross output of non-traded good & 0.58 & OECD STAN (Avg. 1995-1997) \\
$1-\mu$ & share of non-traded good in GDP & 0.75 & match average of country standard de- \\
$\nu$ & controls heterogeneity in distribution services & viations of distribution margins & match average of distribution margins \\
& & & of all goods in country \\
$\zeta_{i}$ & controls country's efficiency in distribution services & & \\
\hline \hline
\end{tabular}

\section{Appendix D}

\subsection{Multi-sector Ricardian Model without Distribution Costs}

The production function of base goods remains the same as in the sectoral model with distribution costs. Sector $t$ intermediate composite $c_{i}^{t}$ is defined as

$$
c_{i}^{t}=\left[\int_{0}^{\infty} \bar{m}_{i}^{t}\left(x^{t}\right)^{\frac{\eta-1}{\eta}} f^{t}\left(z^{t}\right) d z^{t}\right]^{\frac{\eta}{\eta-1}}
$$

where $\bar{m}_{i}^{t}\left(x^{t}\right)$ is the amount of good $x$ of sector $t$ used to produce the intermediate composite of sector $t$, which could be bought from a producer in country $i$ or it could be imported from a producer of another country. $f^{t}\left(z^{t}\right)$ is the joint density function for sector $t$ cost draws. The price of base good $x$ of sector $t$ in country $i$ is given by Eq. (8.1).

The final consumer good is produced using the following production technology

$$
y_{i}=\left[\left(k_{f i}\right)^{\alpha}\left(l_{f i}\right)^{1-\alpha}\right]^{\rho}\left[\prod_{t=1}^{T}\left(c_{i}^{f, t}\right)^{\omega^{t}}\right]^{1-\rho},
$$

such that $\sum_{t=1}^{T} \omega^{t}=1 . \quad k_{f i}$ and $l_{f i}$ are the capital and labor, respectively, used in the production of the final consumer good. $c_{i}^{f, t}$ is the amount of sector $t$ intermediate composite used in the production of the final consumer good. $\rho$ has the same interpretation as in the one-sector model without distribution costs.

The methodology to solve and simulate the model is described below:

Step 1 - Estimate trade costs, $\tau_{i j}^{t}$, and country dummies, $S_{i}^{t}$, using

$$
\begin{gathered}
D_{i j}^{t}=\left(A B^{t}\right)^{-\frac{1}{\theta}}\left(\frac{V_{j}^{t} \tau_{i j}^{t}}{p_{c i}^{t}}\right)^{\frac{-1}{\theta}} \lambda_{j}^{t}, \\
\ln \left(\frac{D_{i j}^{t}}{D_{i i}^{t}}\right)=S_{j}^{t}-S_{i}^{t}-\frac{1}{\theta} \ln \left(\tau_{i j}^{t}\right),
\end{gathered}
$$




$$
\ln \tau_{i j}^{t}=\underbrace{d i s t_{I}}_{\text {distance }}+\underbrace{b r d r}_{\text {border }}+\underbrace{\operatorname{lang}}_{\text {language }}+\underbrace{t b l k_{M}}_{\text {trade block }}+\underbrace{d e s t_{i}^{t}}_{\text {destination effect }}+\varepsilon_{i j}^{t} .
$$

$S_{i}^{t}=\ln \left(\Omega_{i}^{t}\right)$, and $\Omega_{i}^{t}=\left(V_{i}^{t}\right)^{-\frac{1}{\theta}} \lambda_{i}^{t}$.

Step 2 - Compute price of sector $t$ intermediate composite using:

$$
p_{c i}^{t}=A B^{t}\left(\sum_{j=1}^{N} e^{S_{j}^{t}} \tau_{i j}^{t-\frac{1}{\theta}}\right)^{-\theta}
$$

Also compute

$$
\bar{p}_{c i}=\left(\sum_{h=1}^{T}\left(p_{c i}^{h}\right)^{1-\varphi}\right)^{\frac{1}{1-\varphi}} .
$$

Step 3 - Taking $L_{i}$ and $D_{i j}^{t}$ from the data, solve for $l_{i}^{t}$ and $X_{i}^{t}$ as functions of $w_{i}$, and use the balanced trade condition to solve for $w_{i}$.

$$
\begin{gathered}
L_{i} w_{i} l_{i}^{t}=\beta^{t} \sum_{j=1}^{N} L_{j} w_{j}\left[\left(\frac{p_{c j}^{t}}{\bar{p}_{c j}}\right)^{1-\varphi} \sum_{h=1}^{T} \frac{\left(1-\beta^{h}\right)}{\beta^{h}} l_{j}^{h}+\frac{\omega^{t}(1-\rho)}{\rho} l_{f j}\right] D_{j i}^{t}, \\
X_{i}^{t}=\frac{w_{i}}{(1-\alpha)}\left[\left(\frac{p_{c i}^{t}}{\bar{p}_{c i}}\right)^{1-\varphi} \sum_{h=1}^{T} \frac{\left(1-\beta^{h}\right)}{\beta^{h}} l_{i}^{h}+\frac{\omega^{t}(1-\rho)}{\rho} l_{f i}\right], \\
\sum_{t=1}^{T} \sum_{j=1}^{N} L_{j} X_{j}^{t} D_{j i}^{t}=\sum_{t=1}^{T} L_{i} X_{i}^{t} .
\end{gathered}
$$

Labor force share of the final good sector is simply $l_{f i}=\rho$.

Step 4 - The productivity parameter for sector $t$ in country $i, \lambda_{i}^{t}$, is obtained from

$$
\left(V_{i}^{t}\right)^{-\frac{1}{\theta}} \lambda_{i}^{t}=\Omega_{i}^{t}=e^{S_{i}^{t}}
$$

where $V_{i}^{t}$ is the factor cost, given by (8.2). Given the data on capital-labor ratio, $k_{i}$, interest rate is obtained from $r_{i} k_{i}=\frac{\alpha}{1-\alpha} w_{i}$.

Step 5 - I simulate the model by drawing idiosyncratic costs for goods $\left(z_{i}^{t}\left(x^{t}\right)\right)$ from the country-sector specific distribution $\left(\exp \left(\lambda_{i}^{t}\right)\right)$, use Eq. (8.1) to compute the prices of the goods, and then compute LOOP deviations and the cross-country dispersion in LOOP deviations. 

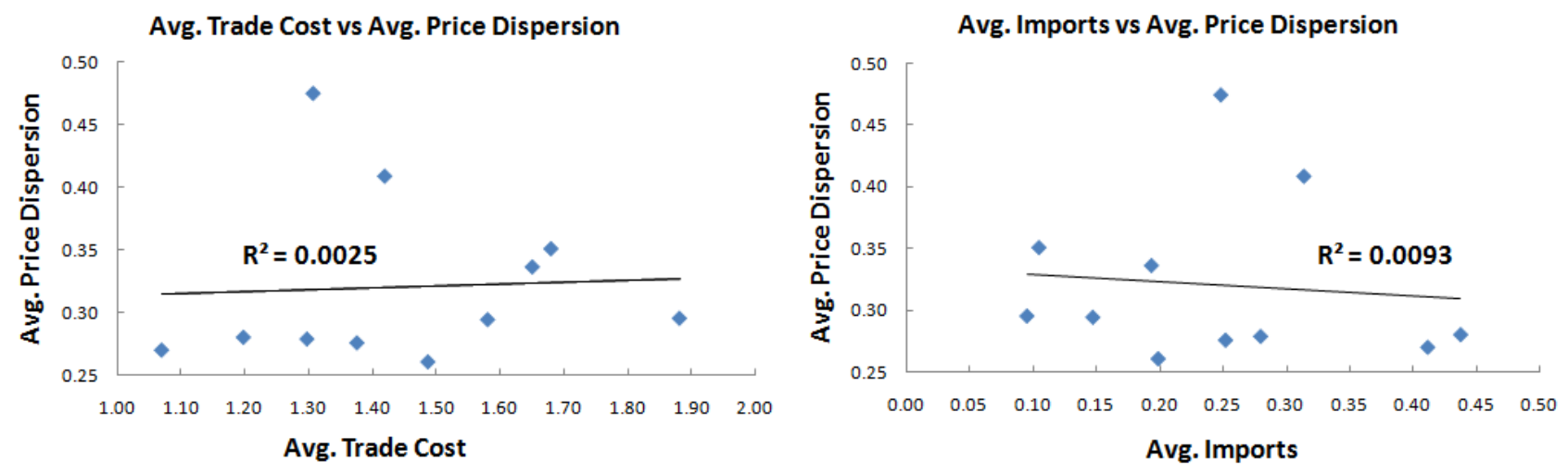

StDev Imports vs StDev Price Dispersion
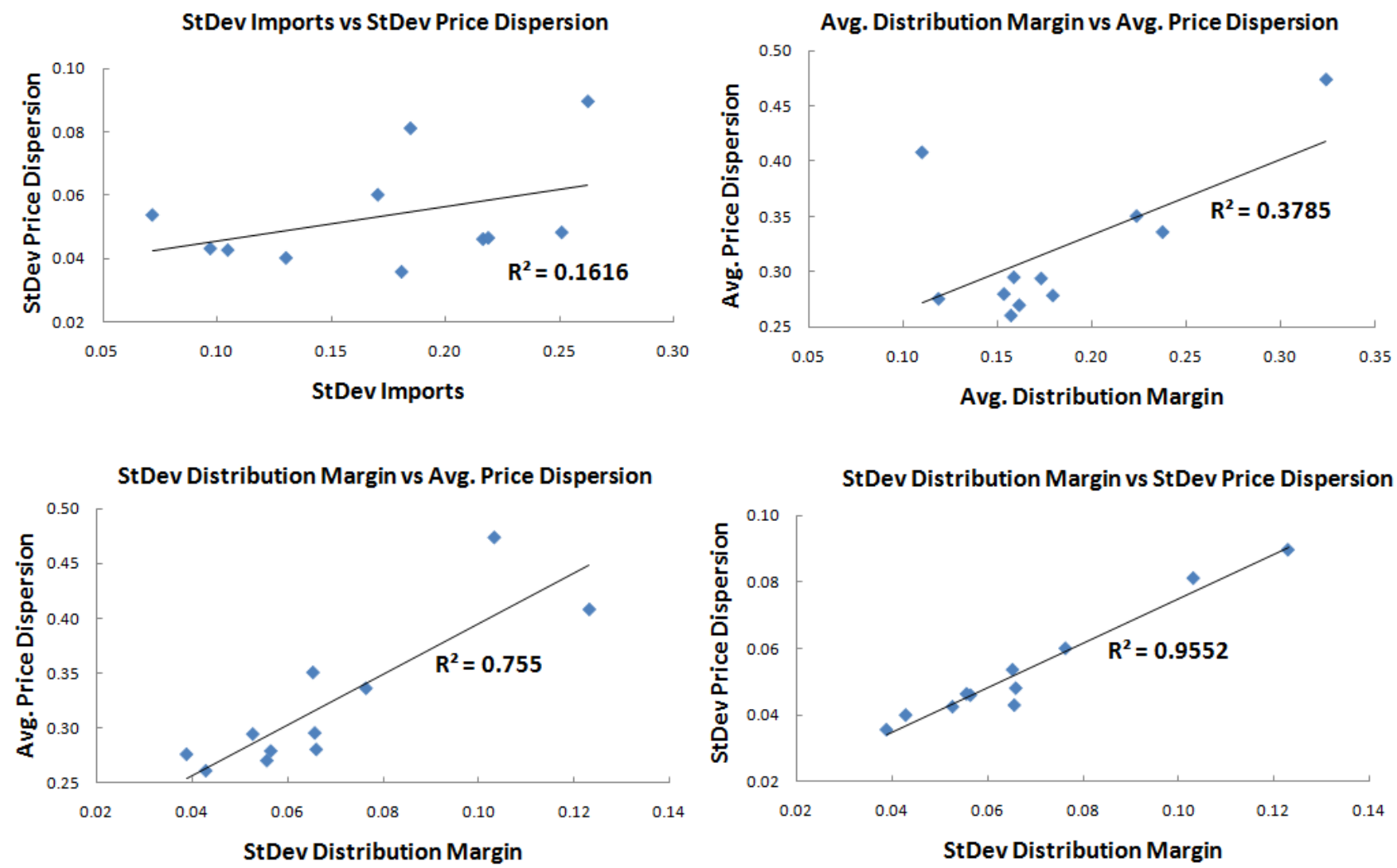

Figure 8: Good-by-good Price Dispersion versus Sources of LOOP by Sector: With Distribution Sector 


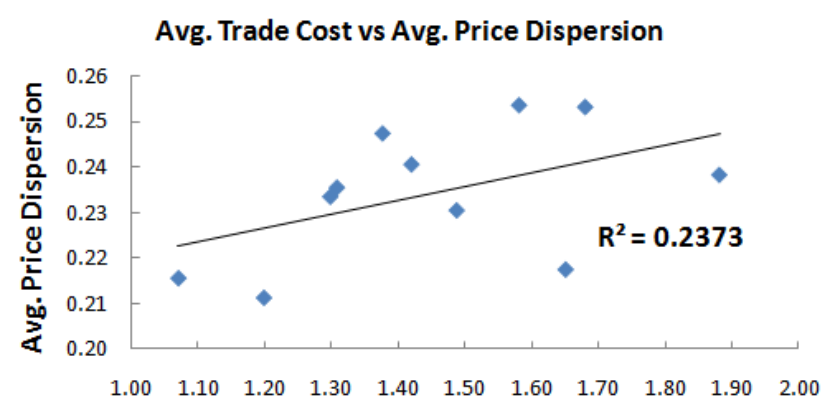

Avg. Trade Cost

Avg. Trade Cost vs StDev Price Dispersion

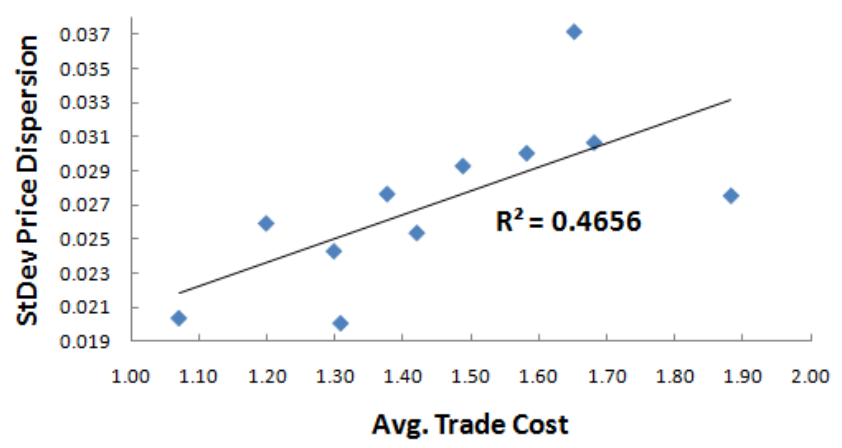

StDev Trade Cost vs StDev Price Dispersion

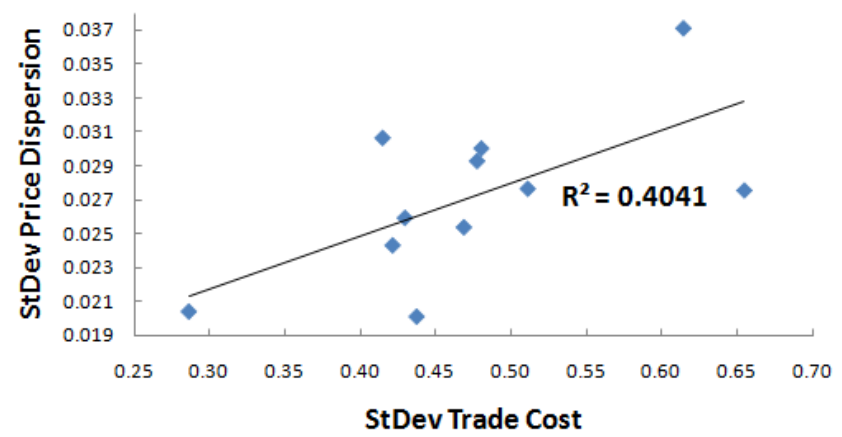

Avg. Imports vs Avg. Price Dispersion

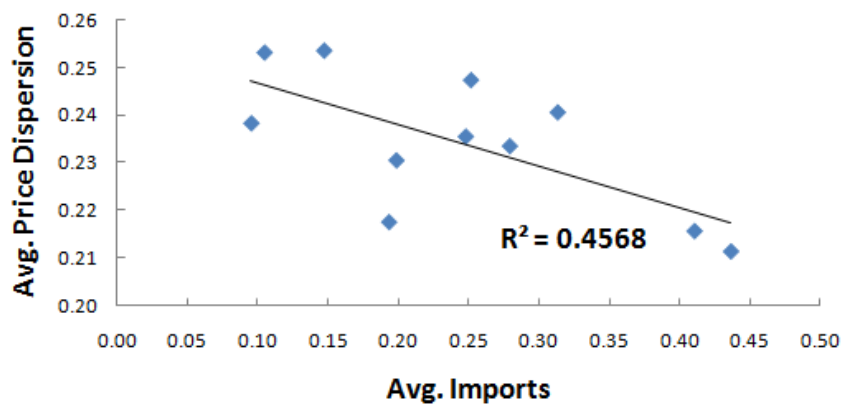

Avg. Imports vs StDev Price Dispersion
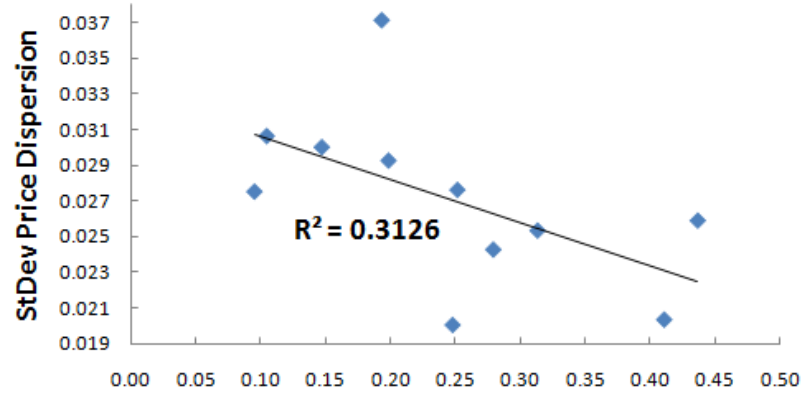

Avg. Imports

StDev Imports vs StDev Price Dispersion

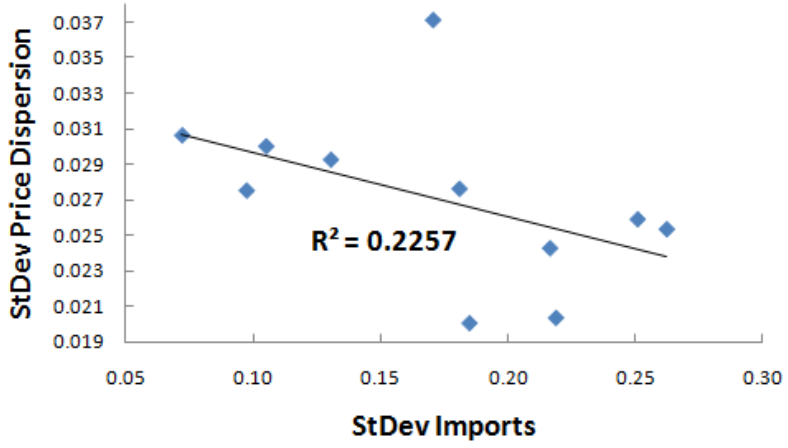

Figure 9: Good-by-good Price Dispersion versus Sources of LOOP by Sector: Without Distribution Sector 